\title{
Structural, Microstructral, Mechanical and Magnetic Characterization of Ball Milled Tungsten Heavy Alloys
}

\author{
H. Elshimy*, Z. K. Heiba, Karimat El-Sayed \\ XRD Unit, Physics Department, Ain Shams University, Cairo, Egypt \\ Email: ${ }^{*}$ hmh elshimy@hotmail.com
}

Received 23 September 2014; revised 8 November 2014; accepted 24 November 2014

Academic Editor: Muhammad Zubair lqbal, Chinese Academy of Sciences (CAS), China

Copyright (C) 2014 by authors and Scientific Research Publishing Inc.

This work is licensed under the Creative Commons Attribution International License (CC BY).

http://creativecommons.org/licenses/by/4.0/

(c) (i) Open Access

\begin{abstract}
A homemade ball mill was constructed and optimized in order to prepare nano crystallite size of tungsten heavy alloys, with composition of $90 \mathrm{~W}-7 \mathrm{Ni}-3 \mathrm{Fe}$ and $90 \mathrm{~W}-7 \mathrm{Ni}-3 \mathrm{Co}$ in wt\%. The samples were mechanically alloyed under high purity of argon atmosphere and were sintered under high vacuumat $1200^{\circ} \mathrm{C}, 1300^{\circ} \mathrm{C}$ and $1400^{\circ} \mathrm{C}$. X-ray diffraction (XRD), Transmission Electron Microscope (TEM), Scanning Electron Microscope (SEM), Energy Dispersive X-ray (EDX), Vickers, ultrasonic techniques and SQUID magnetometer were all used to characterize the studied samples. The sintering temperature and the milling time at which the heavy tungsten alloys were obtained, are discussed in details. The results showed that the tungsten heavy alloys were synthesized and sintered at lower temperature than those prepared by the conventional techniques. Moreover, the strains and relative densities increased with milling time up to 100 hrs; then decreased with further milling. On the other hand, the elastic moduli and hardness increased with milling time up to 200 hrs; then decreased with further milling. The hardness calculated from ultrasonic and measured from Vickers exhibited a similar trend though with different values. The saturated magnetization decreased by increasing the milling time and decreasing the crystallite size.
\end{abstract}

\section{Keywords}

Mechanical Alloying, X-Ray Diffraction, Mechanical Properties, Magnetic Properties

\footnotetext{
"Corresponding author.

How to cite this paper: Elshimy, H., Heiba, Z.K. and El-Sayed, K. (2014) Structural, Microstructral, Mechanical and Magnetic Characterization of Ball Milled Tungsten Heavy Alloys. Advances in Materials Physics and Chemistry, 4, $237-257$. 


\section{Introduction}

Tungsten heavy alloys consist essentially of tungsten (W), with contents (88 - 90) wt\% as a main component, in association with a binder phase containing transition metals (Ni, Fe, Cu, Co) [1]. Nano-sized tungsten heavy alloys offer a unique combination of properties associated with the body centered cubic (BCC) tungsten phase and the face centered cubic (FCC) matrix. High density, high strength, high ductility, high modulus of elasticity, good corrosion resistance, high absorption capacity against X-ray and Gama-Ray and easy machinability are major characteristics [2]-[4]. These properties made such alloys candidate for defense and civilian applications. They are widely used in many fields: 1) the medical; including radiation shielding, source holder, collimator, isotope container and nuclear syringe; 2) the scientific; including tungsten heat sinks, oil drill and mine exploitation; 3) the military; including bullet with sharpened head, balanced ball for missile and plane, etc. and 4) the sports; including golf, fishing, darts, yacht, racing car military [5] [6].

The properties of tungsten heavy alloys are found to be dependent on the amount of tungsten content and on $\mathrm{Ni} / \mathrm{Fe}$ or $\mathrm{Ni} / \mathrm{Cu}$ ratio [7]-[9]. The tungsten heavy alloys with $\mathrm{Ni} / \mathrm{Fe}$ ratio of 4:1 shows best tensile properties and impact strength [7]. However, German and Bourguignon reported that the Ni/Fe ratio of 7:3 was optimal [10]. Bose and Kapoor [8] showed that lowering the W content in the alloys up to $90 \mathrm{wt} \%$ caused an improvement in the ultimate tensile strength as well as elongation value of the sintered WHAs. Katavik and Nikacevic [11] explained that the mechanical properties of W-Ni-Co with nickel to cobalt ratios ranging from 2 to 9 are far superior to that of $\mathrm{W}-\mathrm{Ni}-\mathrm{Fe}$ alloys.

WHAs with W content 90\% - 95\% possess good combination of tensile properties (tensile strength-1000 MPa and elongation-30\%), as well as, high density of 17 - $18 \mathrm{~g} / \mathrm{ml}$ [10]. Because of their high density, these alloys find wide applications. Besides, WHAs with tungsten content of 90 - 97 mass \% can be used to substitute the uranium-depleted alloys as a core material for kinetic energy penetrators [12].

Numerous investigations have been carried out in order to improve the properties of tungsten heavy alloys as well as lowering the sintering temperature by refining the microstructure of tungsten alloy. Previous studies have shown that sintering temperature is related to the powder size; such that when the size is in nano-scale, the sintering temperature is decreased up to several hundreds of degrees [13]. The mechanical alloying technique was developed by Benjamin [14] as an advanced fabrication process that can cheaply produce powders with ultra-fine grains and homogeneous microstructures [15] [16].

An optimized homemade ball mill, suitable for producing homogenized nanocrystallite sizes from tungsten heavy alloys was designed and constructed in our laboratory. The microstructural parameters (crystallite size and strains) were investigated in the aim of reaching reasonable nanocrystallite size. The hardness measurements were used as indictor for the mechanical properties of the sintered material using Hardness Vickers technique. In addition, the ultra sonic technique was used to determine the elastic moduli beside the hardness. All the obtained results were correlated with each other.

\section{Experimental Procedure}

\subsection{The Sample Preparation}

The as received Tungsten powder of $2.46 \mu \mathrm{m}$, Nickel powder of $2.3 \mu \mathrm{m}$, Cobalt powder of $2.4 \mu \mathrm{m}$ and Iron powder of $2.1 \mu \mathrm{m}$ (in average size)were used in this study. Two samples of tungsten heavy alloy powder with composition $90 \mathrm{~W}-7 \mathrm{Ni}-3 \mathrm{Fe}$ and $90 \mathrm{~W}-7 \mathrm{Ni}-1.5 \mathrm{Fe}-3 \mathrm{Co}$ in $\mathrm{wt} \%$ were mechanically alloyed by using the home made ball millfor 50, 100, 150, 200 and 400 hrs. The mill consists of two rotators connected to a motor of maximum rotation speed $1000 \mathrm{rpm}$ and the vial rotates at the same speed as the tray, but in the opposite direction, Figure 1. The vial is a cylinder of stainless steel with diameter $3.8 \mathrm{~cm}$ and height $7.5 \mathrm{~cm}$. The parameters used for the milling conditions are: stainless steel rods of diameter $6 \mathrm{~mm}$, milling speed of 175 rpm, powder charge ratio of 20:1 and filling factor of 30\%. The mechanical alloying was performed under high purity of argon atmosphere in order to prevent oxidation during milling.

The milled powder of the two tungsten samples, obtained at different milling times, were cold pressed into a cylindrical die by using a hydraulic press at ambient temperature and under pressure up to $600 \mathrm{Mpa}$. The final green compacts were cylindricalin shape with dimensions: diameter $=8.0 \mathrm{~mm}$ and length $=6.0 \mathrm{~mm}$, with tolerance of $\pm 1 \mathrm{~mm}$.

The green compacts were divided into three groups, the first group was sintered at a temperature of $1200^{\circ} \mathrm{C}$, the second was sintered at $1300^{\circ} \mathrm{C}$ and the third was sintered at $1400^{\circ} \mathrm{C}$. The sintering process was performed in vacuum furnace and the samples were held for a constant time of 60 minutes. 


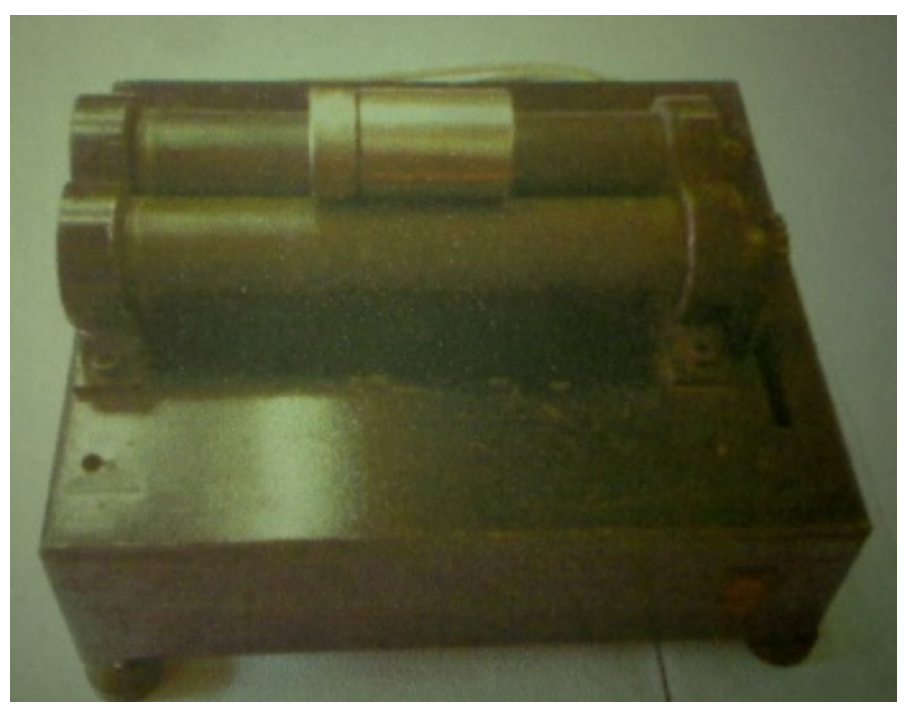

Figure 1. The home made ball mill.

\subsection{Sample Characterization}

A PHILIPS ${ }^{\circledR}$ X'Pert diffractometer, which has the Bragg-Brentano geometry and Copper tube, was used to collect the XRD patterns for the different samples. The operating voltage was kept at $40 \mathrm{kV}$ and the current at 30 $\mathrm{mA}$. The divergence-slit angle $=1^{\circ}$, the receiving slit $=0.1^{\circ}$, the step scan size $=0.03^{\circ}$ and the scan step time $=5$ seconds. The $\mathrm{K}_{\beta}$ radiation was eliminated using the secondary monochromator at the diffracted beam.

The structural and the microstructural parameters (such as the lattice parameters, crystallite size, RMS lattice strain and the percentage of phases present) of all samples have been made by employing the Rietveld software MAUD [17] [18]. In order to obtain the real crystallite size, the instrumental broadening was determined using the standard reference material LaB6. The XRD data collections for all samples were carried out at the same setting condition. A JEOL 1230 transmission electron microscope (TEM), operating at $120 \mathrm{kV}$ and attached to a CCD camera, and a scanning electron microscope (SEM), attached to energy dispersive X-ray spectroscopy (EDX) operating at $30 \mathrm{kV}$, were used to investigate the studied samples. The densities of the sintered alloys, at different temperatures, were measured by Archimedes method. The hardness was measured by using Vickers Microhardness tester, type Shemad $\mathrm{Zu}$. All hardness measurements were performed at a load of $100 \mathrm{gm}$ and pressing time 10 seconds, The measurements were repeated three times at different sample locations in order to reach accurate samples. Ultrasonic Testing (UT) with high frequency sound energy was used for material characterization. The velocities (Longitudinal, $v_{l}$, and transverse, $v_{s}$ ) were calculated by dividing the round trip distance $(2 X)$ by the elapsed time $(\Delta t)$ according to the relation

$$
U=\frac{2 X}{\Delta t}
$$

where $X$ is the sample thickness and $\Delta t$ is the time interval.

The Elastic Moduli (Young $E$, Shear $G$ and Bulk $K$ ), the Poisson ratio $\sigma$ and the Hardness $H$ were calculated from the following equations [19] [20].

$$
\begin{gathered}
\text { Young's Modulus } E=\frac{9 K G}{3 K+G} \\
\text { Shear Modulus } G=\rho v_{s}^{2} \\
\text { Bulk Modulus } K=\rho\left(v_{l}^{2}-\frac{4}{3} v_{s}^{2}\right) \\
\text { Poisson ratio } \sigma=\frac{E-2 G}{2 G}
\end{gathered}
$$


The Hardness $H=\frac{(1-2 \sigma)}{6(1+\sigma)} E$

where $\rho$ is the density, $v_{l}$ and $v_{s}$ are the longitudinal and transverse ultrasonic velocities, respectively. The ultrasonic velocities in the sample were measured using an ultrasonic flow detector, type USM 2 (Krautkramer, Germany). All measurements in this study were carried out at room temperature and at a frequency of $5 \mathrm{MHz}$ for shear velocities and $10 \mathrm{MHz}$ for the longitudinal velocities. The measurements were repeated five times to check the reproducibility of the data.

\section{Result and Discussion}

\subsection{Structural and Microstructural Characterization of Mechanically Alloyed Powders}

\subsubsection{X-Ray Diffraction}

The X-ray diffraction patterns of the mechanically alloyed powder of 90W-7Ni-3Fe and 90W-7Ni-3Co are shown in Figure 2 and Figure 3, respectively, for different milling times. It is evident that, the diffraction peaks

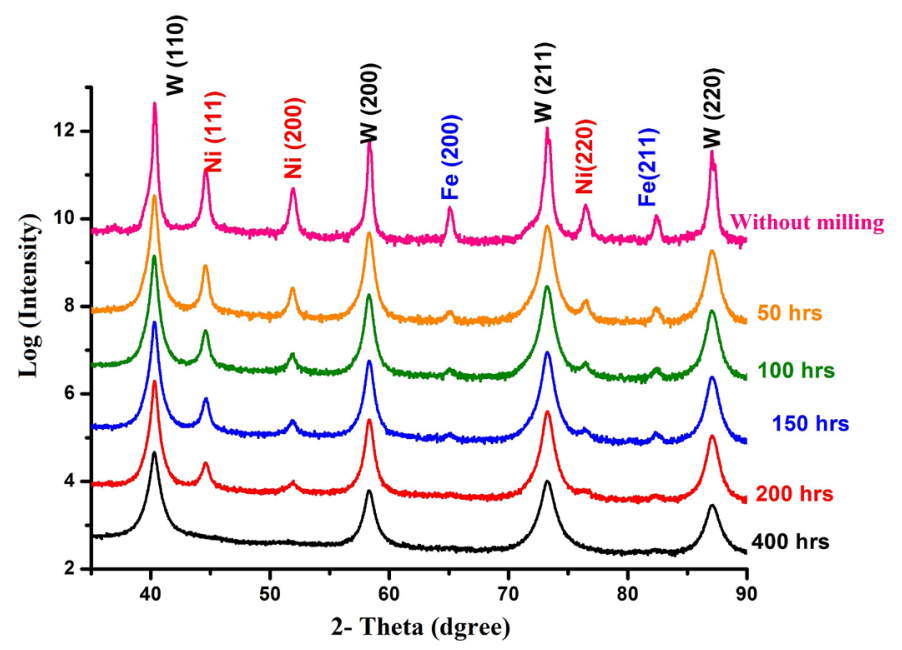

Figure 2. XRD patterns for $90 \mathrm{~W}-7 \mathrm{Ni}-3 \mathrm{Fe}$ (wt\%) powders milled for different times.

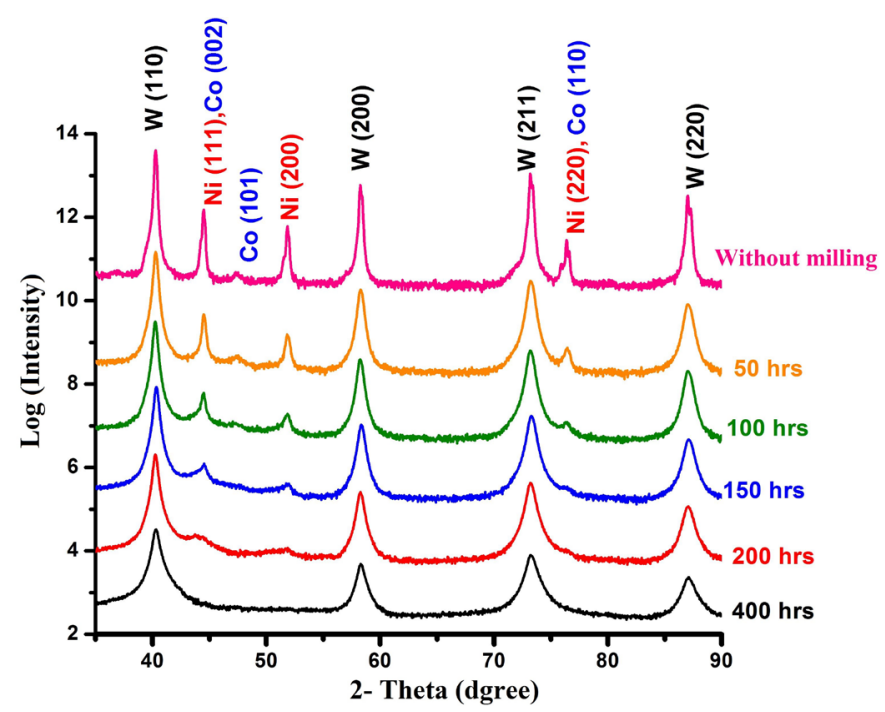

Figure 3. XRD patterns for 90W-7Ni-3Co (wt\%) powders milled for different times. 
became gradually broadened and the peak intensities decreased with the increase of milling time. These observations indicate that both the crystallite sizes and microstrains of the mixed powders are significantly affected by the mechanical milling. From the figures, it appears that there are no new phases or foreign diffraction peaks are present at different milling times. Selected refined patterns are presented in Figure 4 and Figure 5. The Bragg residual factor, $\mathrm{R}_{\mathrm{B}}$ and the goodness of fitting, GOF of all the fitted patterns, lie within $(4.6-7.5) \%$ and $(1.4$ - 2.9) respectively for $90 \mathrm{~W}-7 \mathrm{Ni}-3 \mathrm{Fe}$; and lie within $(4.8-7.4) \%$ and $(1.5-2.8)$ respectively for the $90 \mathrm{~W}-$ 7Ni-3Co. Figure 6(a) shows the influence of milling time on the tungsten crystallite size in the Fe and Co alloys respectively. After 50 hrs, the mechanical milling leads to a fast decrease in the crystallite size; it varies from 81 $\mathrm{nm}$ for the $90 \mathrm{~W}-7 \mathrm{Ni}-3 \mathrm{Fe}$ alloy, to $75 \mathrm{~nm}$ for the 90W-7Ni-3Co alloy. As the milling time increased, the trend of the rate of the crystallite decrease became less obvious [21]. At $200 \mathrm{hrs}$, the crystallite size is nearly the same as that of $150 \mathrm{hrs}$, suggesting that the rate of milling is approximately equal to the rate of agglomeration. When milling time reached $400 \mathrm{hrs}$, further decrease in crystallite size occurred at a much slower rate up to about 25 $\mathrm{nm}$ for the $90 \mathrm{~W}-7 \mathrm{Ni}-3 \mathrm{Fe}$ alloy and $18 \mathrm{~nm}$ for the $90 \mathrm{~W}-7 \mathrm{Ni}-3 \mathrm{Co}$ alloy.

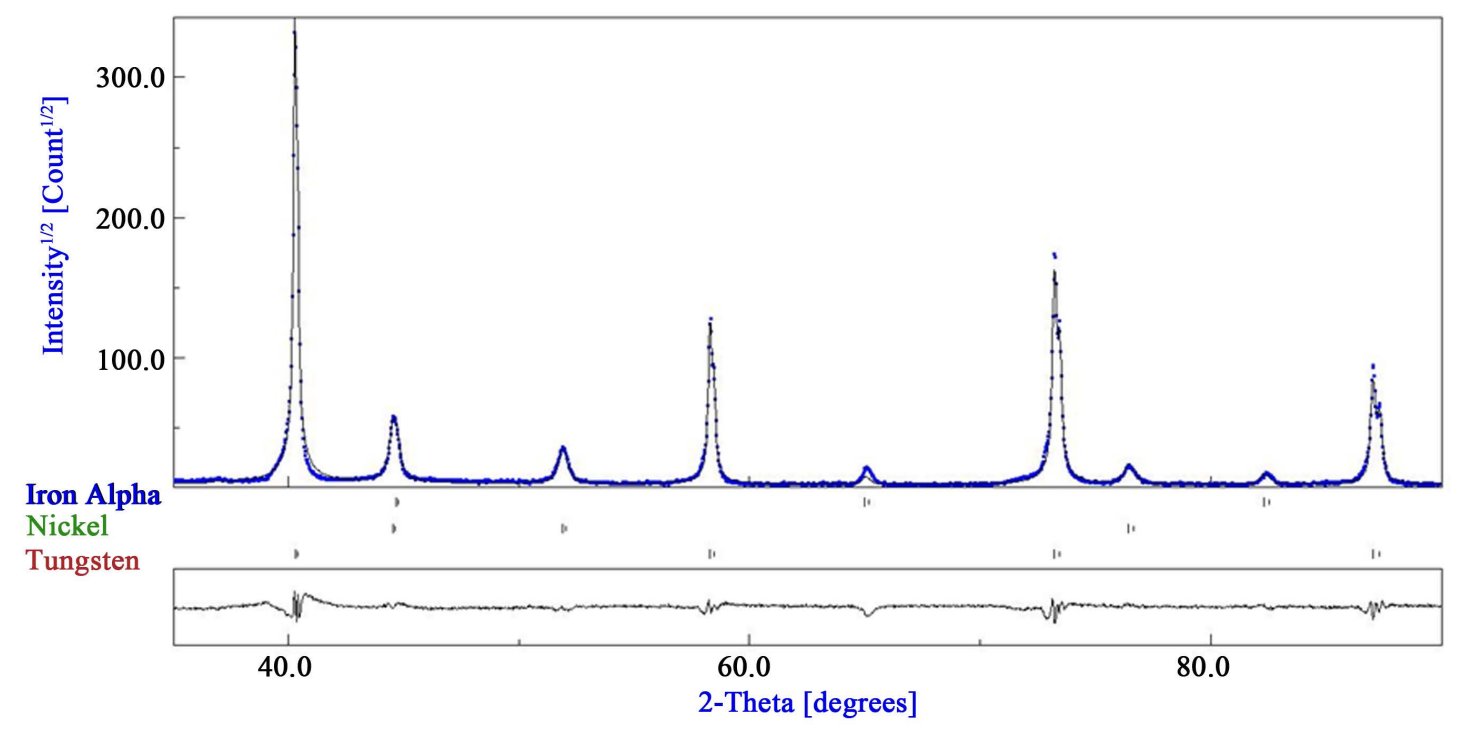

(a)

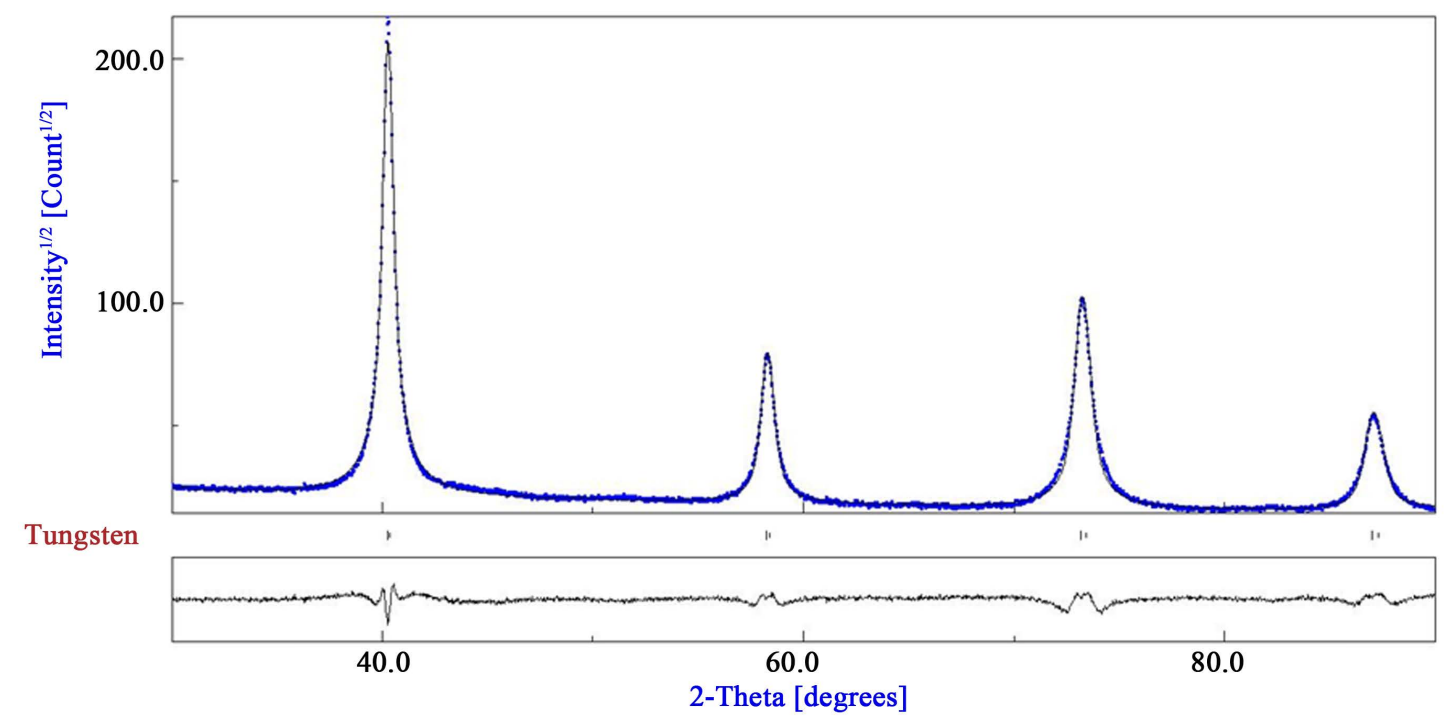

(b)

Figure 4. Rietveld refinement of the XRD pattern of the 90W7Ni-3Fe powders. (a) Unmilled; (b) Milled for 400 hrs. 


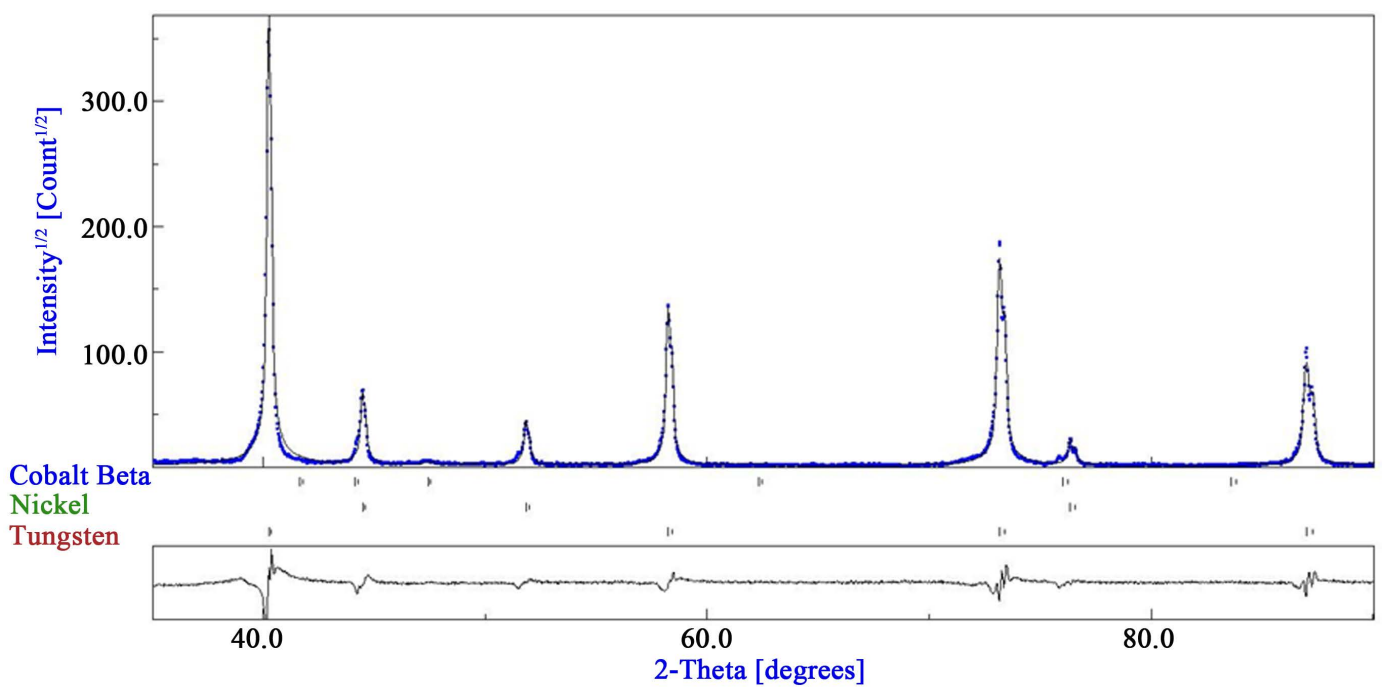

(a)

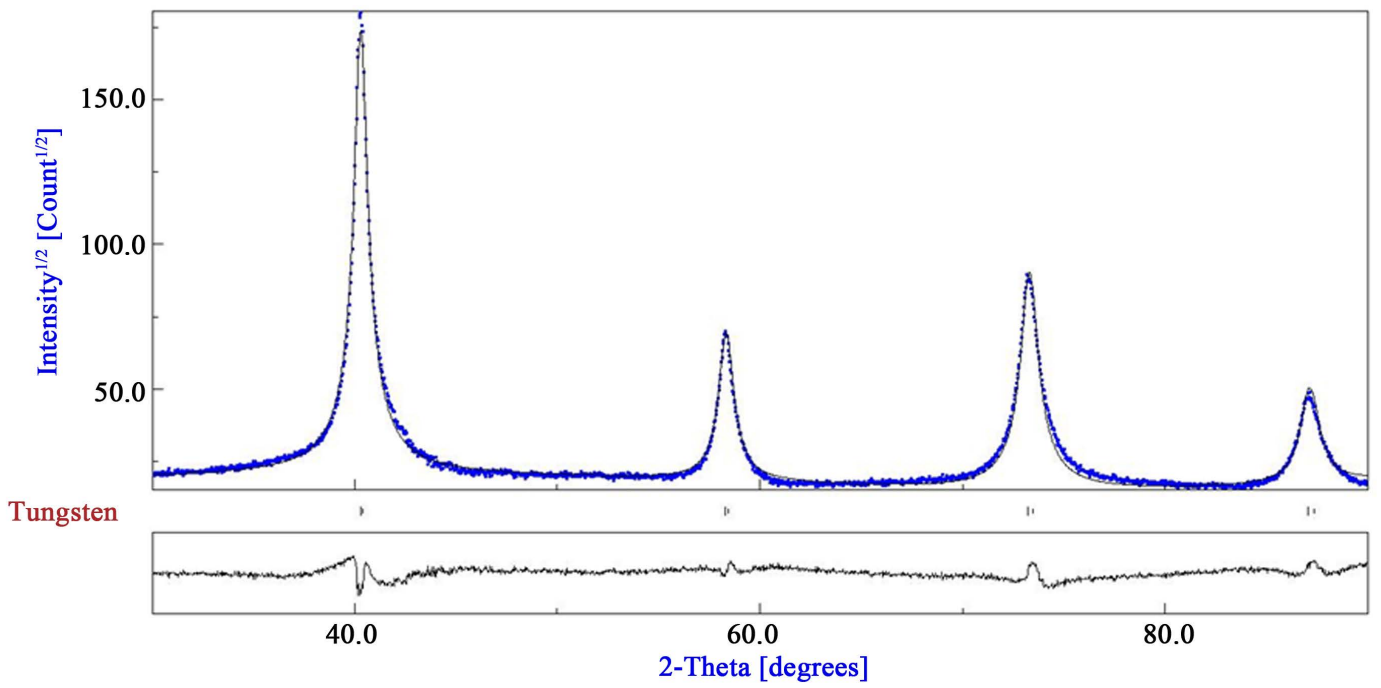

(b)

Figure 5. Rietveld refinement of the XRD pattern of the 90W7Ni-3Co powders. (a) Unmilled; (b) Milled for 400 hrs.

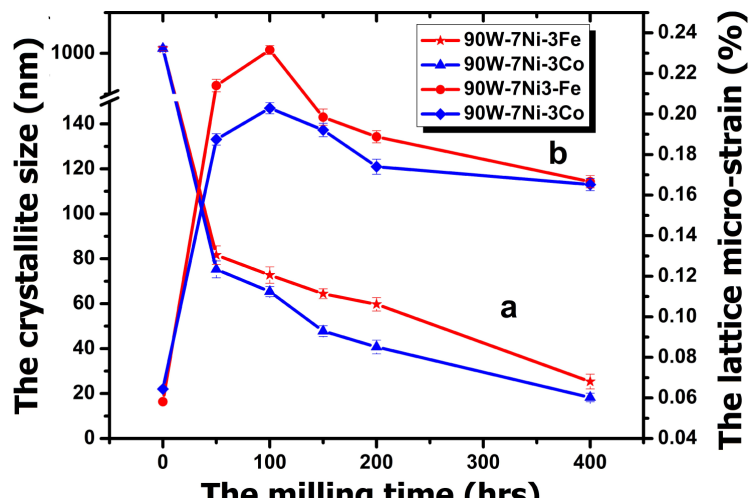

Figure 6. The effect of the milling time on (a) crystallite size and (b) the microstarin for the $\mathrm{Fe}$ and $\mathrm{Co}$ alloys. 
Figure 6(b) shows the influence of milling time on the microstrains of the tungsten in both Fe and Co alloys respectively. At a milling time of $100 \mathrm{hrs}$, the lattice strain increased by about $0.23 \%$ for the $90 \mathrm{~W}-7 \mathrm{Ni}-3 \mathrm{Fe}$ alloy, while the increase reached only $0.20 \%$ for the $90 \mathrm{~W}-7 \mathrm{Ni}-3 \mathrm{Co}$ alloy. Such increase is probably mainly due to the increase in the lattice defects during milling. Further milling causes the lattice strains to decrease significantly. This decrease became substantial after longer times of milling. The heat energy generated by the mechanical impact of the steel rods causes fast grain boundary diffusion that acts as an annealing effect which in turn leads to an increase in the crystallite size and a decrease in the strain i.e. minimizing the strains [22].

The volume fraction of the elemental composition (W, Ni, Fe or Co) calculated from XRD patterns as a function of milling time, is exhibited in Figure 7(a) and Figure 7(b). Upon increasing the milling time, the tungsten content increases while the Ni, Fe or Co contents decrease. The results obtained from Rietveld refinement revealed no change in the tungsten lattice parameters, as shown in Figure 8. This eliminated the diffusion of the $\mathrm{Ni}, \mathrm{Fe}$ or Co atoms into the $\mathrm{W}$ lattice whether by substitution or by interstitial. On the other hand, the $\mathrm{Ni}$, Fe or Co atoms could have probably formed an amorphous phase on the grain boundary of the tungsten element; thus suggesting the implanting tungsten nanoparticles in an amorphous phase matrix composed of $\mathrm{Ni}$ and $\mathrm{Fe}$ or $\mathrm{Ni}$ and Co.
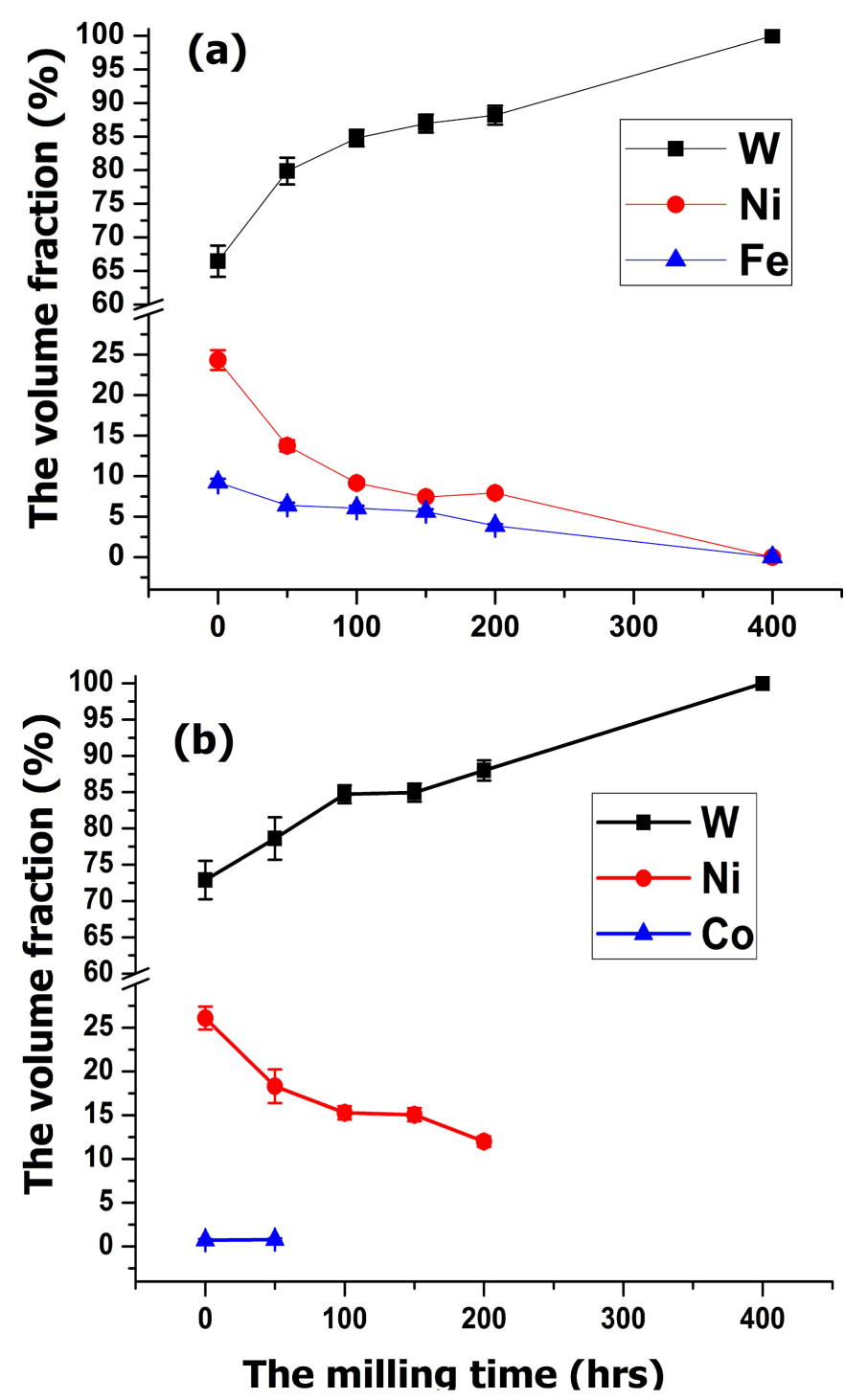

Figure 7. The variation of the volume fraction with milling time (a) for the $90 \mathrm{~W}-7 \mathrm{Ni}-3 \mathrm{Fe}$ sample and (b) for the 90W-7Ni-3Co sample. 

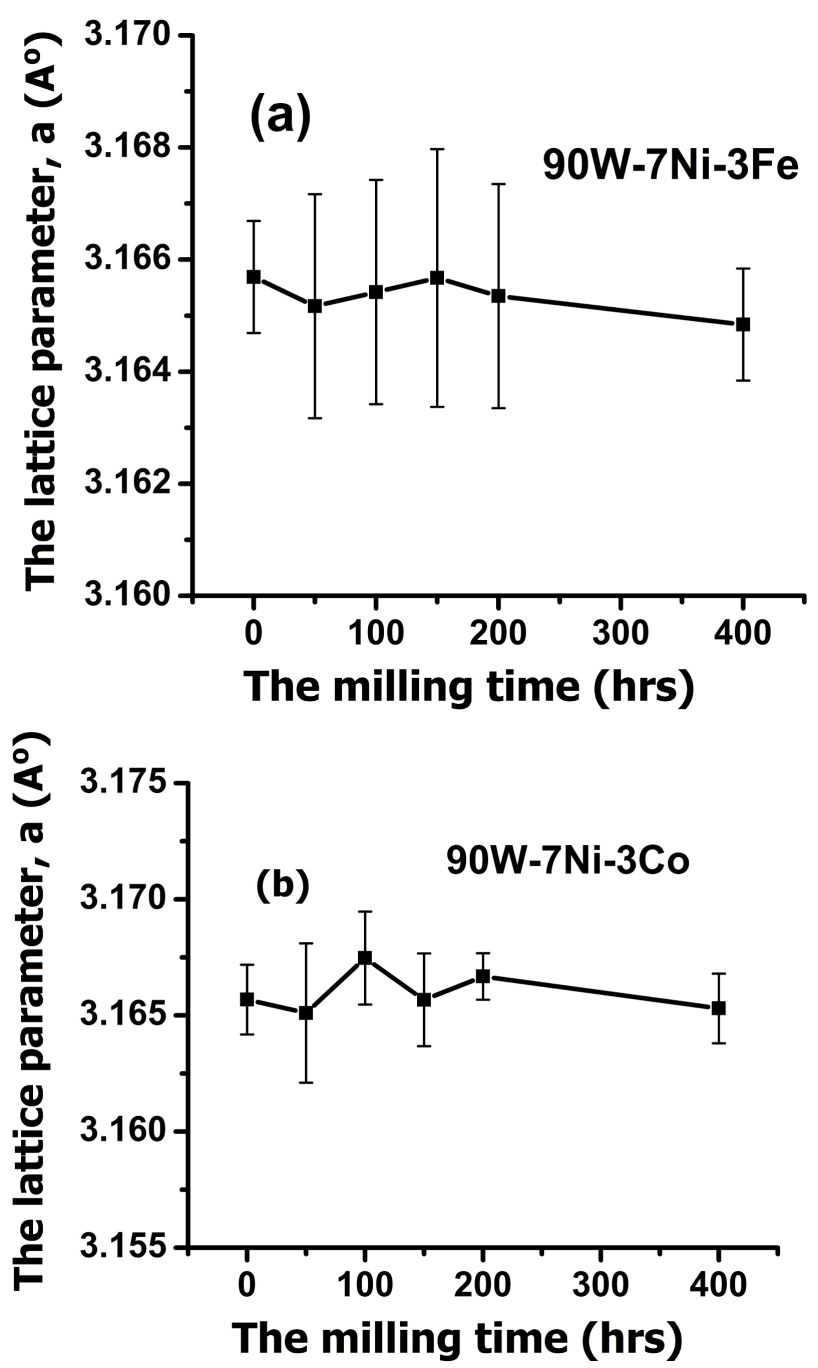

Figure 8. The variation of the $\mathrm{W}$ lattice parameter with milling time.

\subsubsection{TEM and EDX Characterization}

The TEM nanocrystallite size of the milled 90W-7Ni-3Fe powders at different times is shown in Figures 9(a)-(c). Figure 9(a) shows the sample after milling for 50 hrs, where the nanocrystallite sizes have nearly spherical morphology with average size $97 \mathrm{~nm}$. This value is in agreeable with that obtained by using the XRD analysis for the same sample. Upon further milling, a significant amount of agglomeration is observed after 150 and 200 hrs, as given in Figure 9(b) and Figure 9(c). This behavior could be attributed to the agglomeration of fine nanocrystallites [23]. The (TEM) results of nanocrystallite size of the milled 90W-7Ni-3Co appear in Figures 9(d)-(f), which exhibit a similar trend as that depicted for the $90 \mathrm{~W}-7 \mathrm{Ni}-3 \mathrm{Fe}$ alloy.

The results of EDX analysis from different locations on the samples showed that the elemental percentage of the milled powders is very close to the initial composition. In turn this suggests that all elements were uniformly distributed throughout the matrix of the synthesized alloy. Eventually, this guarantees the minimization of the contamination. Moreover, it enhances the validity of the constructed homemade ball.

\subsubsection{Powder Compaction}

Green density is highly dependent on the friction forces among powder particles. These forces mainly result from electrostatic, Van der Waals and surface adsorption forces that become much more significant with decreasing particle size [24]. The results shown in Figure 10 clearly demonstrate the influence of milling time, and hence the particle size, on relative density. 

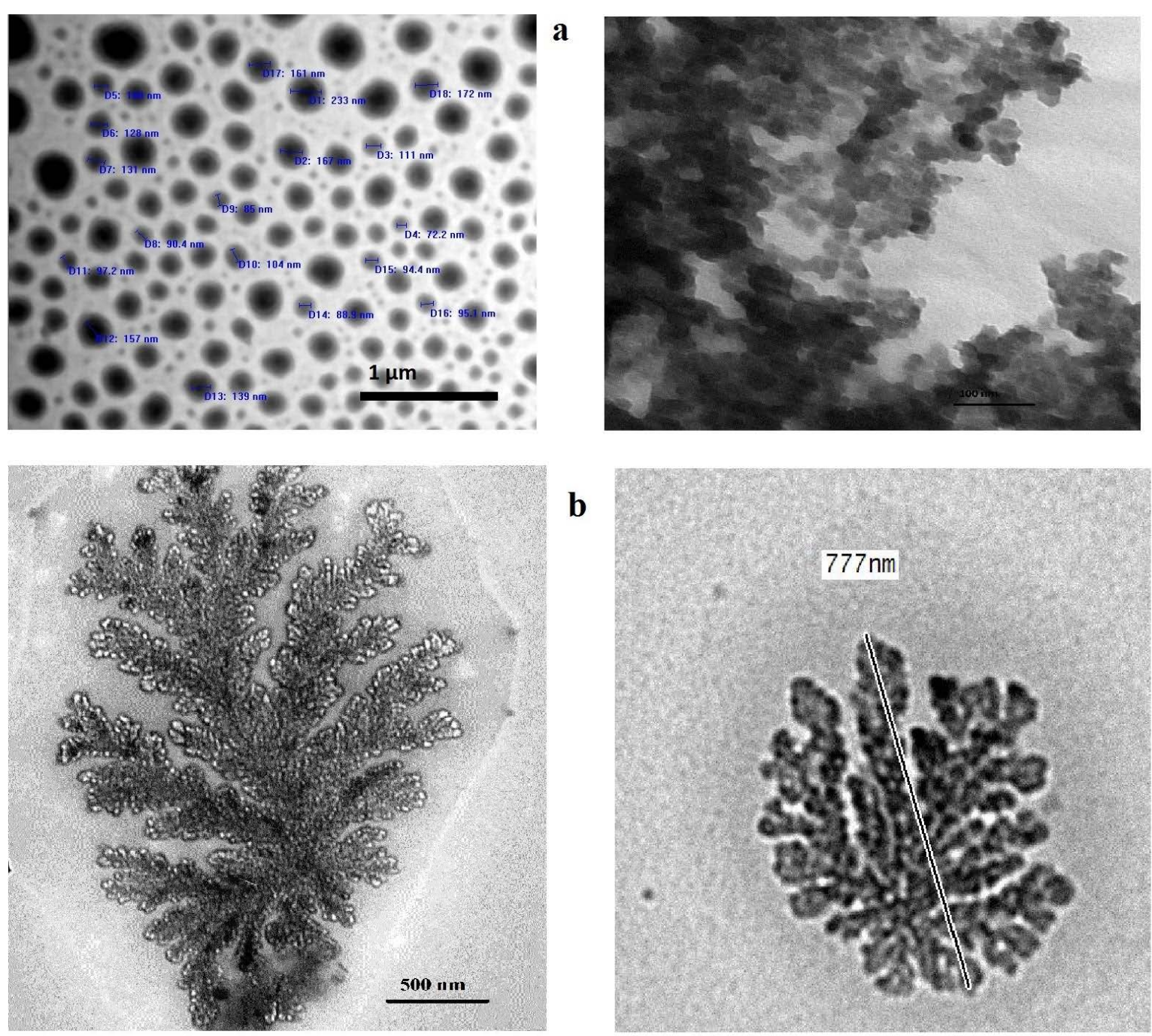

b
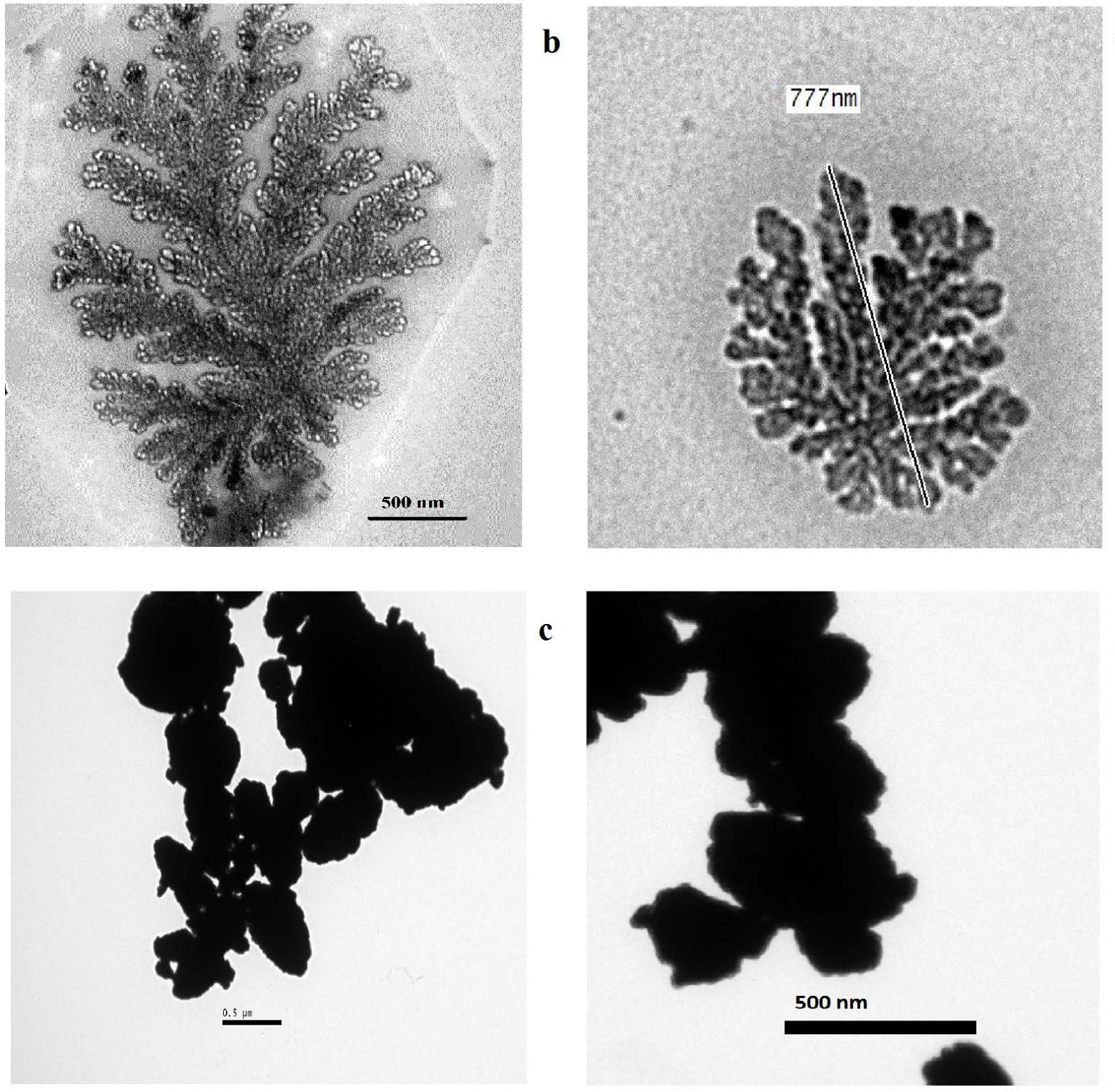

Figure 9. The TEM microstructure of the 90W-7Ni-3Fe powders milled for (a) 50 hrs; (b) 150 hrs; (c) 200 hrs and the microstructure of 90W-7Ni-3Co powder milled for (d) 50 hrs; (e) 150 hrs and (f) 200 hrs. 


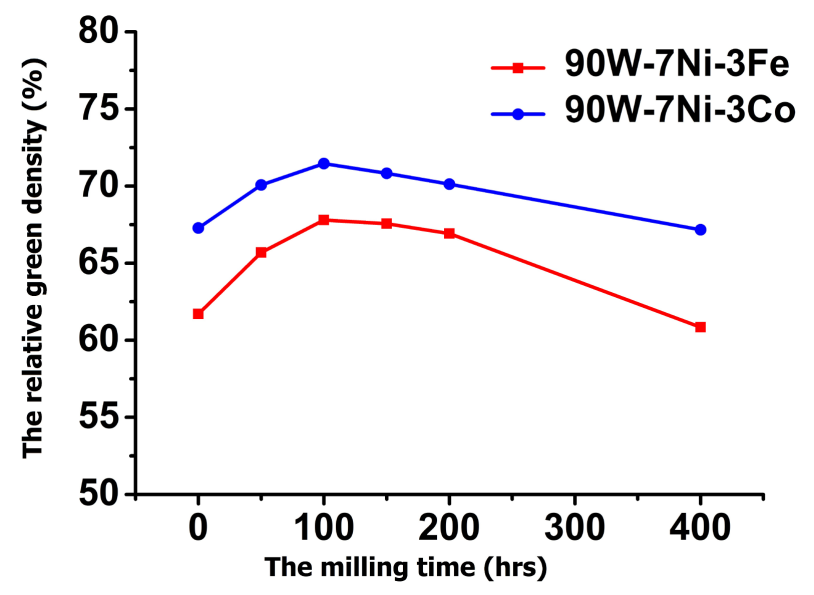

Figure 10. Influence of milling time on the relative green densities.

After 100 hrs of milling, the relative green density reached a maximum value of $67.8 \%$ for the $90 \mathrm{~W}-7 \mathrm{Ni}-3 \mathrm{Fe}$ composition and $71.5 \%$ for the $90 \mathrm{~W}-7 \mathrm{Ni}-3 \mathrm{Co}$ composition. While further increasing of the milling time, the green densities decreased due to of the effect of decreasing the particle size with milling time, thus causing an increase in the friction forces among the powder particles [25].

\subsection{Structural and Microstructural Characterization of Sintered Alloys}

\subsubsection{X-Ray Diffraction}

$\mathrm{X}$-ray diffraction was used, in case of sintered samples, to identify the phase formation of the tungsten heavy alloy at the different sintering temperature. At sintering temperatures $1300^{\circ} \mathrm{C}$ and $1400^{\circ} \mathrm{C}$, the qualitative analysis of the XRD patterns confirmed the formation of the tungsten heavy alloy for the two compositions, 90W$7 \mathrm{Ni}-3 \mathrm{Fe}$ and $90 \mathrm{~W}-7 \mathrm{Ni}-3 \mathrm{Co}$, regardless of whether the powders are milled or not. Some of the selected XRD patterns are presented in Figure 11.

At sintering temperature $1200^{\circ} \mathrm{C}$, the tungsten heavy alloys are formed for powders milled at 100 hrs and above as a result of fine, smaller and homogenous powders, moreover the benefit of the high pressure [26]; Figure 12. In the case of unmilled and $50 \mathrm{hrs}$ milled powders, the individual elemental peaks ( $\mathrm{Ni}, \mathrm{Fe})$ for 90W-7Ni-3Fe were still vivid indicating that no solid solution was formed, Figure 13.

\subsubsection{SEM Investigation}

To obtain further microstructural information, SEM is well suited to identify the existing phases, their shapes and their homogeneity. Investigations were carried on the two alloys 90W-7Ni-3Fe and 90W-7Ni-3Co alloys of unmilled powders as well as sintered at $1200^{\circ} \mathrm{C}, 1300^{\circ} \mathrm{C}$ and $1400^{\circ} \mathrm{C}$. In addition, the investigations included the alloys of powder milled for $200 \mathrm{hrs}$ and sintered at the previously indicated temperature. The most prominent features of the micrographs are the size distribution and the homogeneity of the binder phase among the tungsten phase. Figures 14(a)-(f) and Figures 15(a)-(f) illustrate the micrographs of polished and etched specimens of the 90W-7Ni-3Fe and 90W-7Ni-3Co alloys, respectively. These specimens were fabricated from unmilled and 200 hrs milled powders, sintered at different temperatures. The SEM micrographs show that at the different sintering temperatures, the microstructures of the unmilled (90W-7Ni-3Fe) and (90W-7Ni-3Co) alloys consist of coarse primary particles and the distribution of nickel and iron (cobalt) are concentrated in certain areas while other areas are almost free. But for the 200 hrs milled alloys, the homogeneity of the binder phase is observed to be finer due to the fine grain size of powders; as a benefit of mechanical alloying.

EDX analysis was carried out along with SEM in order to investigate the chemical composition of particles after sintering, and to ensure the absence of oxygen which could have been produced during the sintering process. The alloys of unmilled powder, those of milled for 200 and $400 \mathrm{hrs}$, all sintered at $1400^{\circ} \mathrm{C}$ were chosen as test samples.

The EDX spectrum of the two alloys, the 90W-7Ni-3Fe and 90W-7Ni-3Co, after milling for 200 hrs and sintered at $1400^{\circ} \mathrm{C}$, are displayed in Figure 16 . The results of percentage content of the various elements for these alloys are shown in Table 1. 


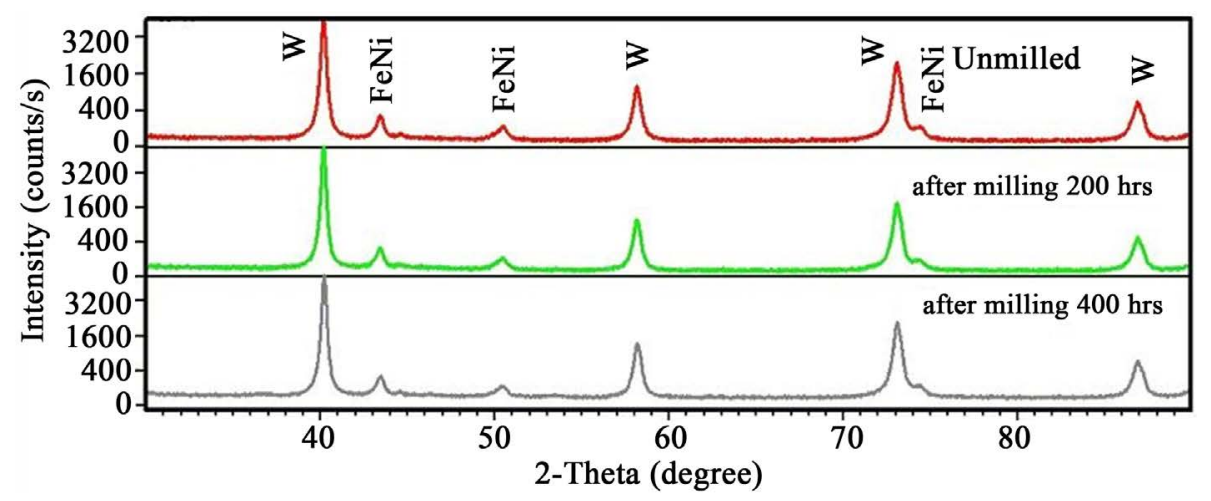

Figure 11. XRD patterns for $90 \mathrm{~W}-7 \mathrm{Ni}-3 \mathrm{Fe}$ alloy sintered at $1400^{\circ} \mathrm{C}$.

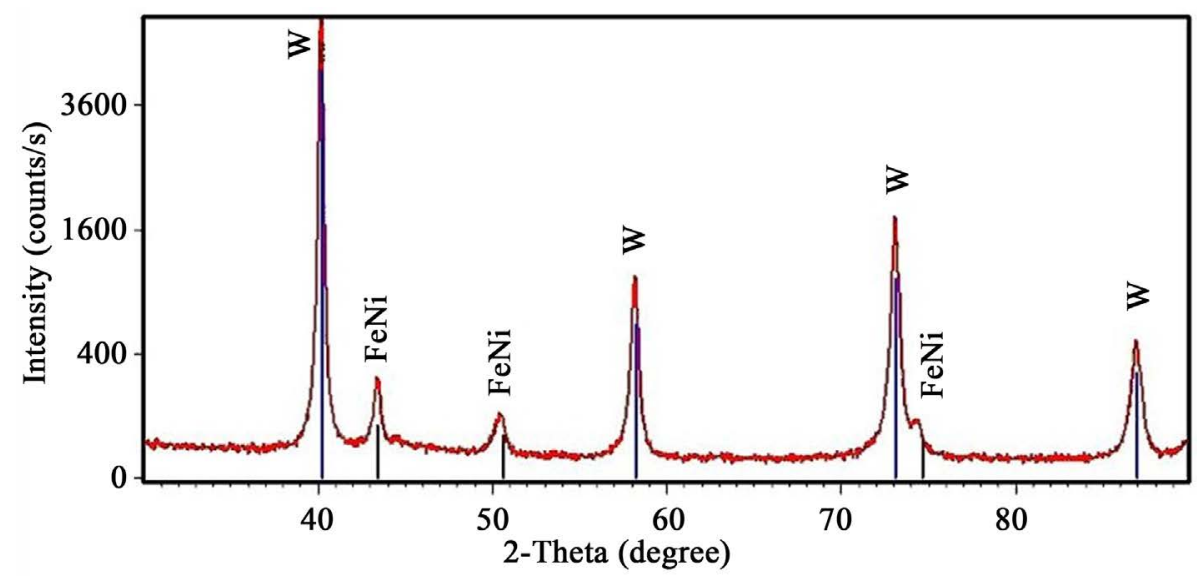

Figure 12. XRD patterns for $90 \mathrm{~W}-7 \mathrm{Ni}-3 \mathrm{Fe}$ alloy milled for $100 \mathrm{hrs}$ and sintered at $1200^{\circ} \mathrm{C}$.

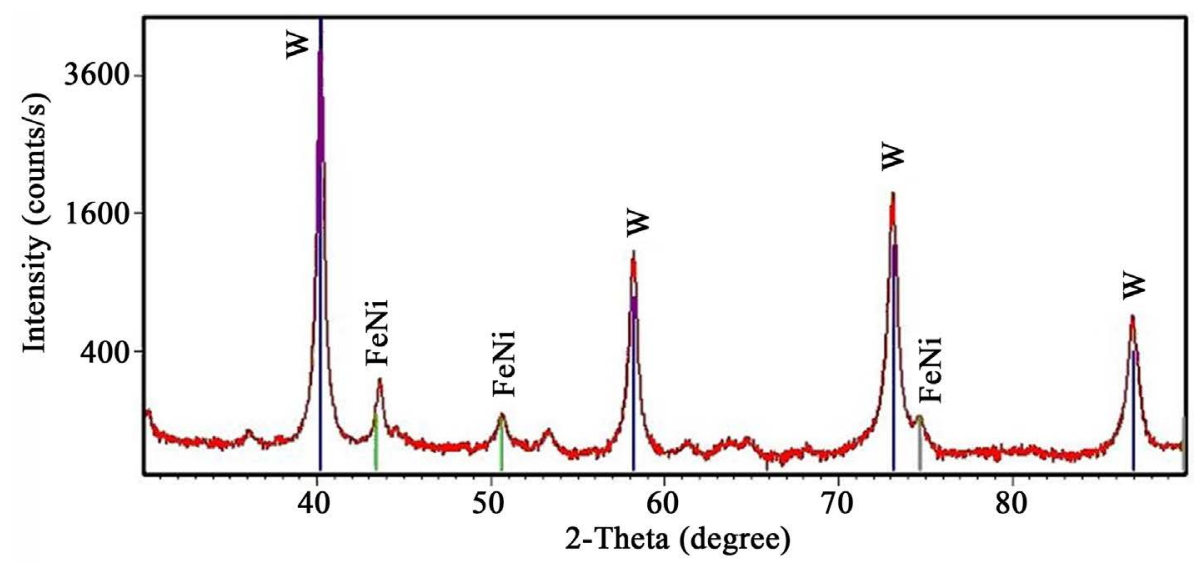

Figure 13. XRD patterns for the unmilled $90 \mathrm{~W}-7 \mathrm{Ni}-3 \mathrm{Fe}$ alloy sintered at $1200^{\circ} \mathrm{C}$.

Table 1. Elements contents of alloys of unmilled powder and powder milled for 200 and 400 hrs and sintered at $1400^{\circ} \mathrm{C}$.

\begin{tabular}{cccccccc}
\hline Milling time & \multicolumn{3}{c}{ 90W-7Ni-3Fe } & & \multicolumn{3}{c}{ 90W-7Ni-3Co } \\
\hline & W\% & Ni\% & Fe\% & W\% & Ni\% & Co\% \\
\hline Unmilled & 91.6 & 4.14 & 4.26 & 85.05 & 10.51 & 4.44 \\
200 hrs & 89.16 & 7.62 & 3.22 & 89.10 & 7.06 & 7.94 & 3.69 \\
400 hrs & 88.7 & 7.14 & 4.16 & 88.37 & \\
\hline
\end{tabular}




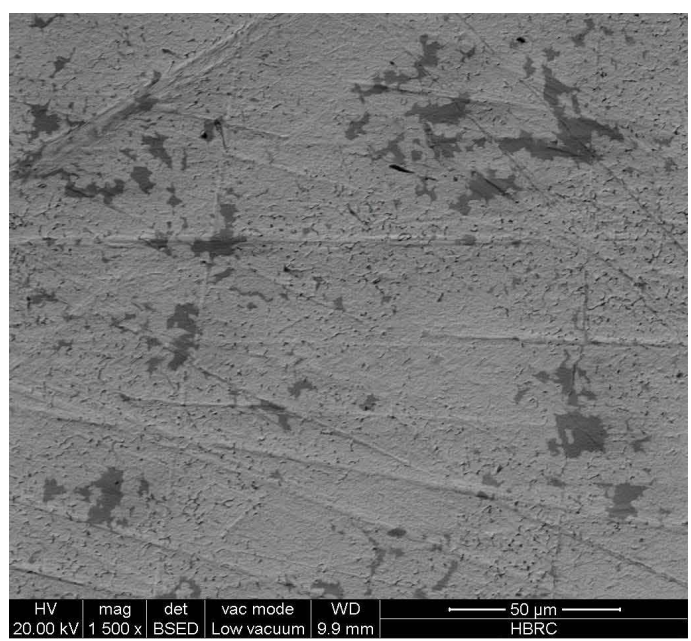

(a)

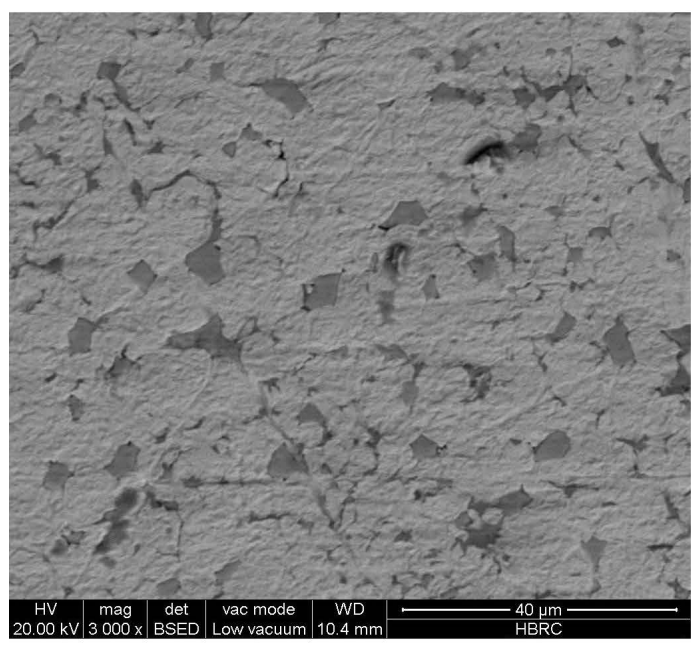

(c)

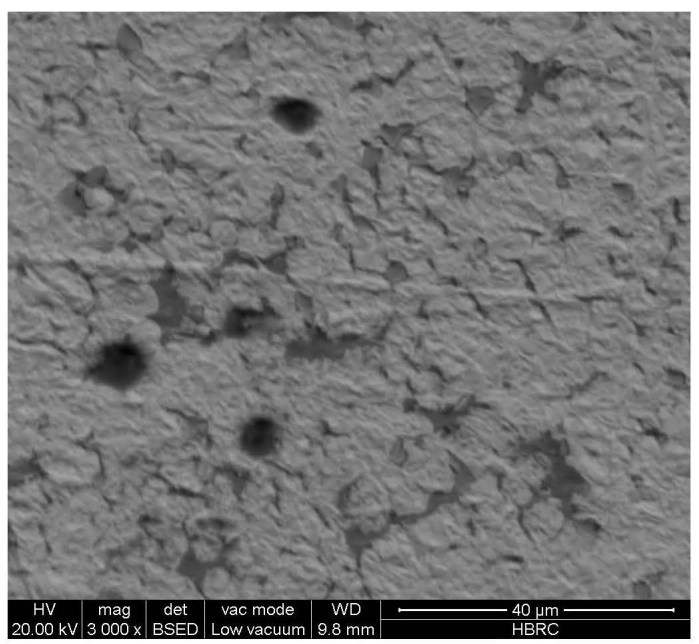

(e)

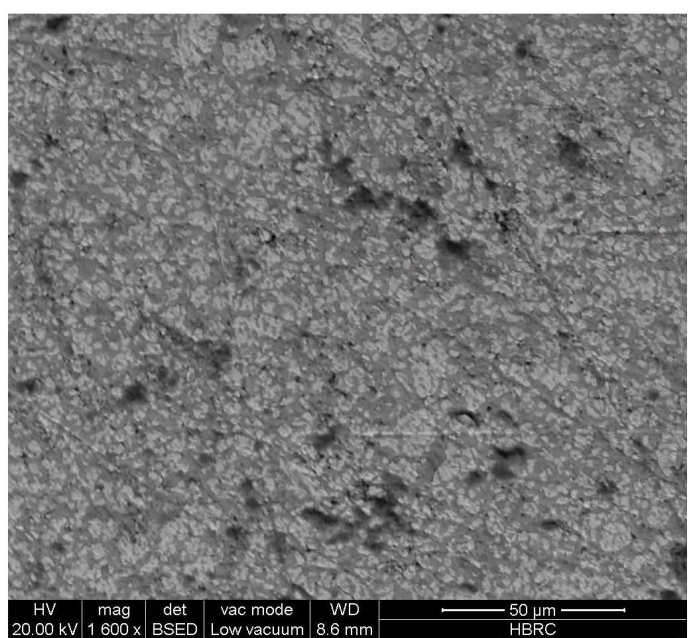

(b)

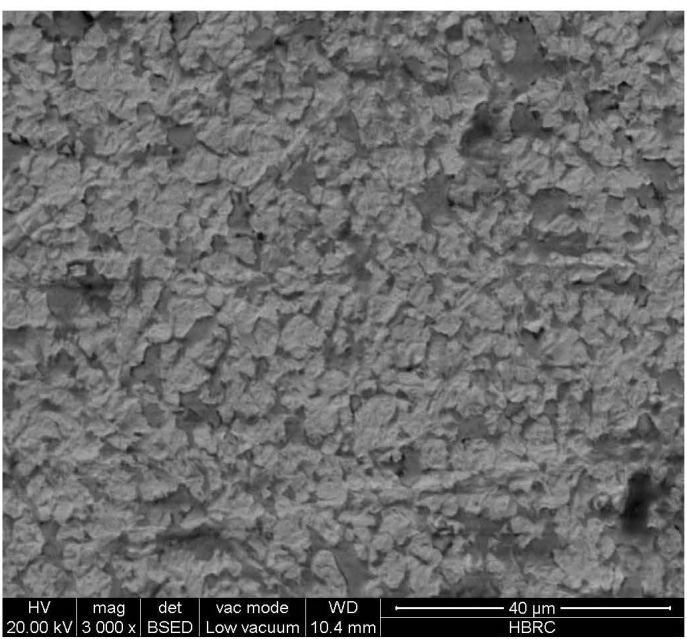

(d)

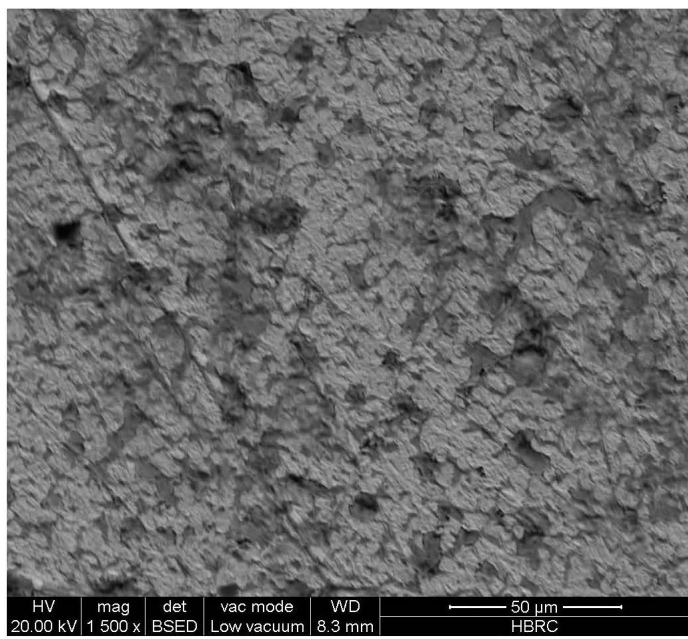

(f)

Figure 14. SEM micrograph of 90W-7Ni-3Fe sintered alloy. (a) Unmilled, at $1200^{\circ} \mathrm{C}$; (b) Milled for $200 \mathrm{hrs}$, at $1200^{\circ} \mathrm{C}$; (c) Unmilled, at $1300^{\circ} \mathrm{C}$; (d) Milled for $200 \mathrm{hrs}$, at $1300^{\circ} \mathrm{C}$; (e) Unmilled, at $1400^{\circ} \mathrm{C}$; (f) Milled for $200 \mathrm{hrs,}$ at $1400^{\circ} \mathrm{C}$. 


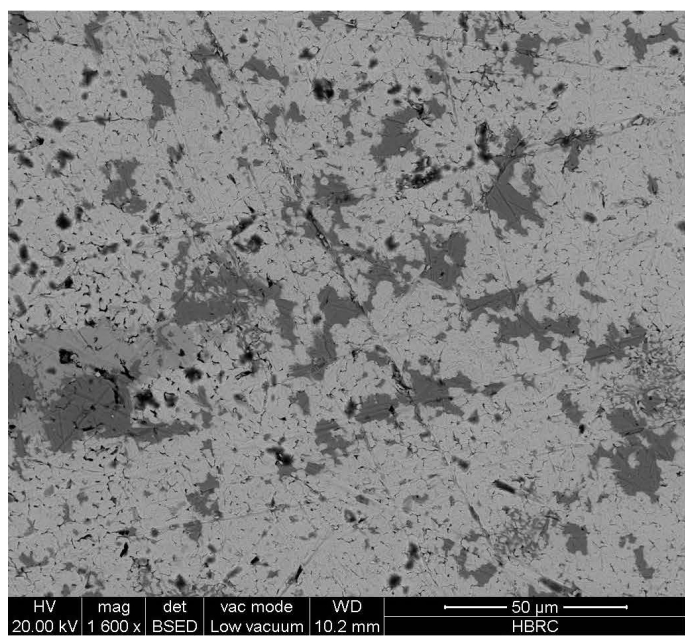

(a)

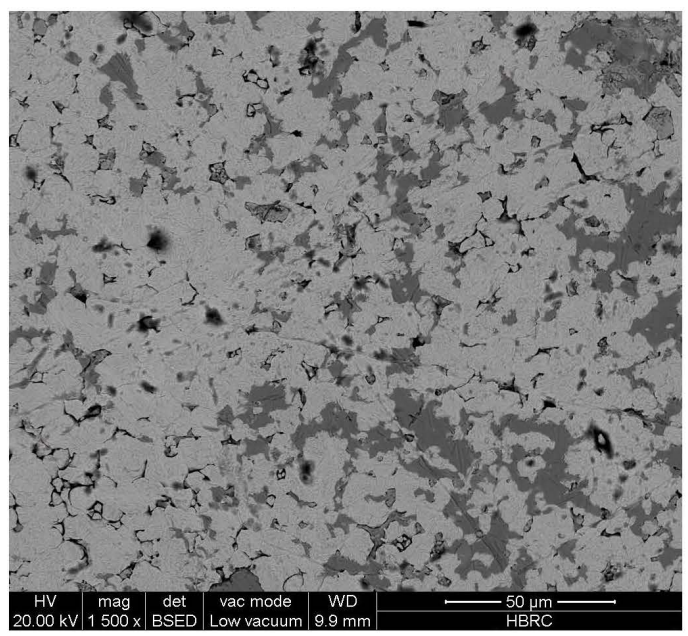

(c)

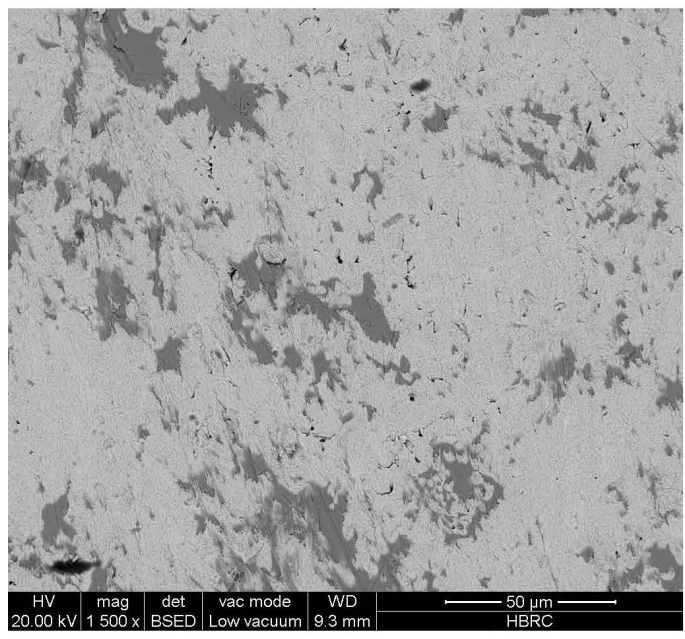

(e)

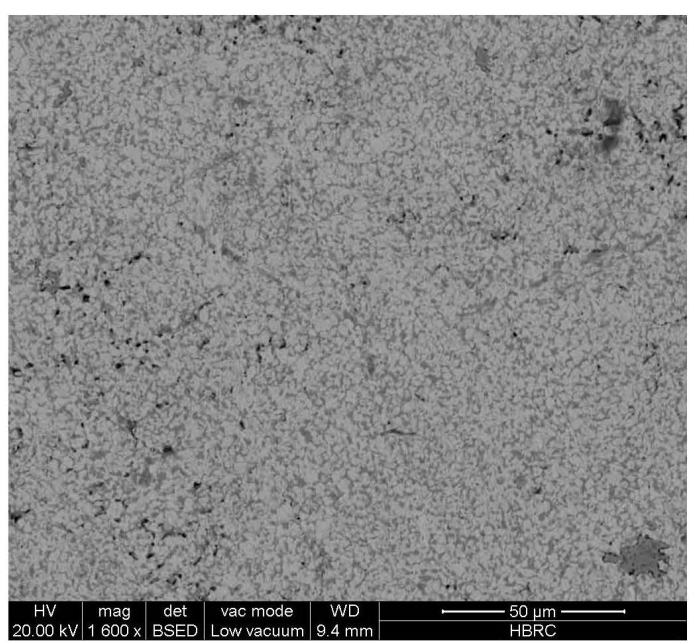

(b)

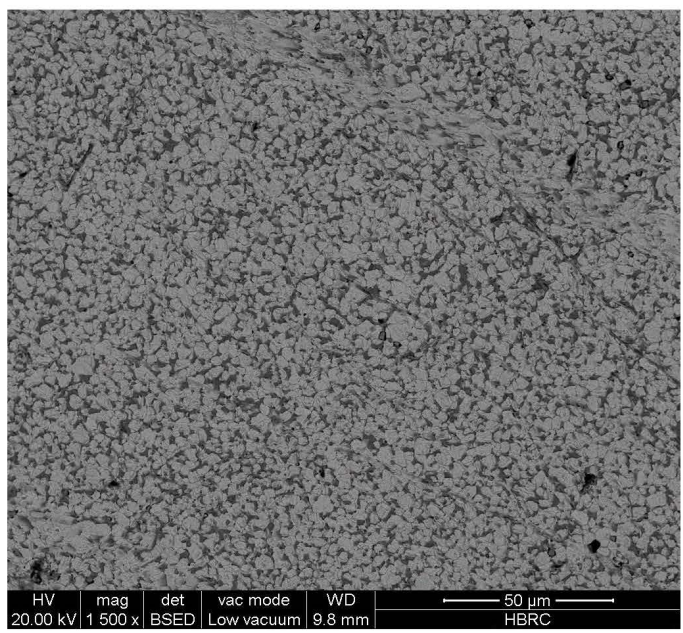

(d)

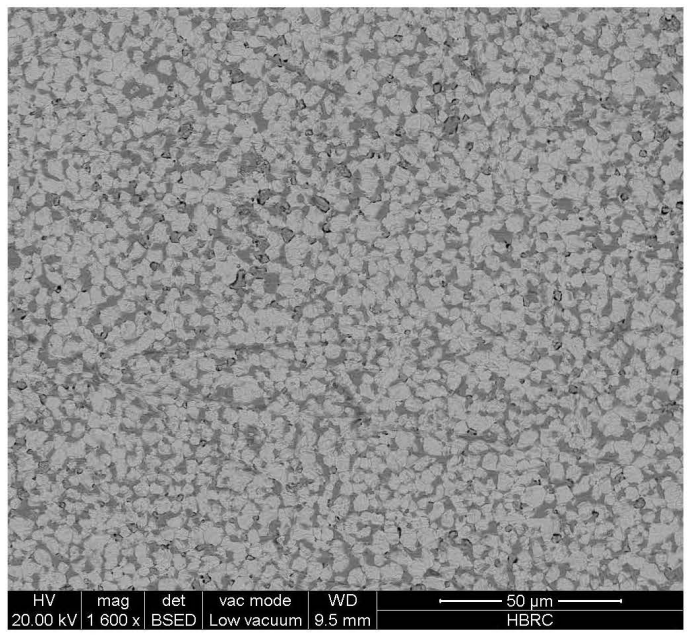

(f)

Figure 15. SEM micrograph of 90W-7Ni-3Co sintered alloy. (a) Unmilled, at $1200^{\circ} \mathrm{C}$; (b) Milled for 200 hrs, at $1200^{\circ} \mathrm{C}$; (c) Unmilled, at $1300^{\circ} \mathrm{C}$; (d) Milled for $200 \mathrm{hrs}$, at $1300^{\circ} \mathrm{C}$; (e) Unmilled, at $1400^{\circ} \mathrm{C}$; (f) Milled for $200 \mathrm{hrs,}$ at $1400^{\circ} \mathrm{C}$. 

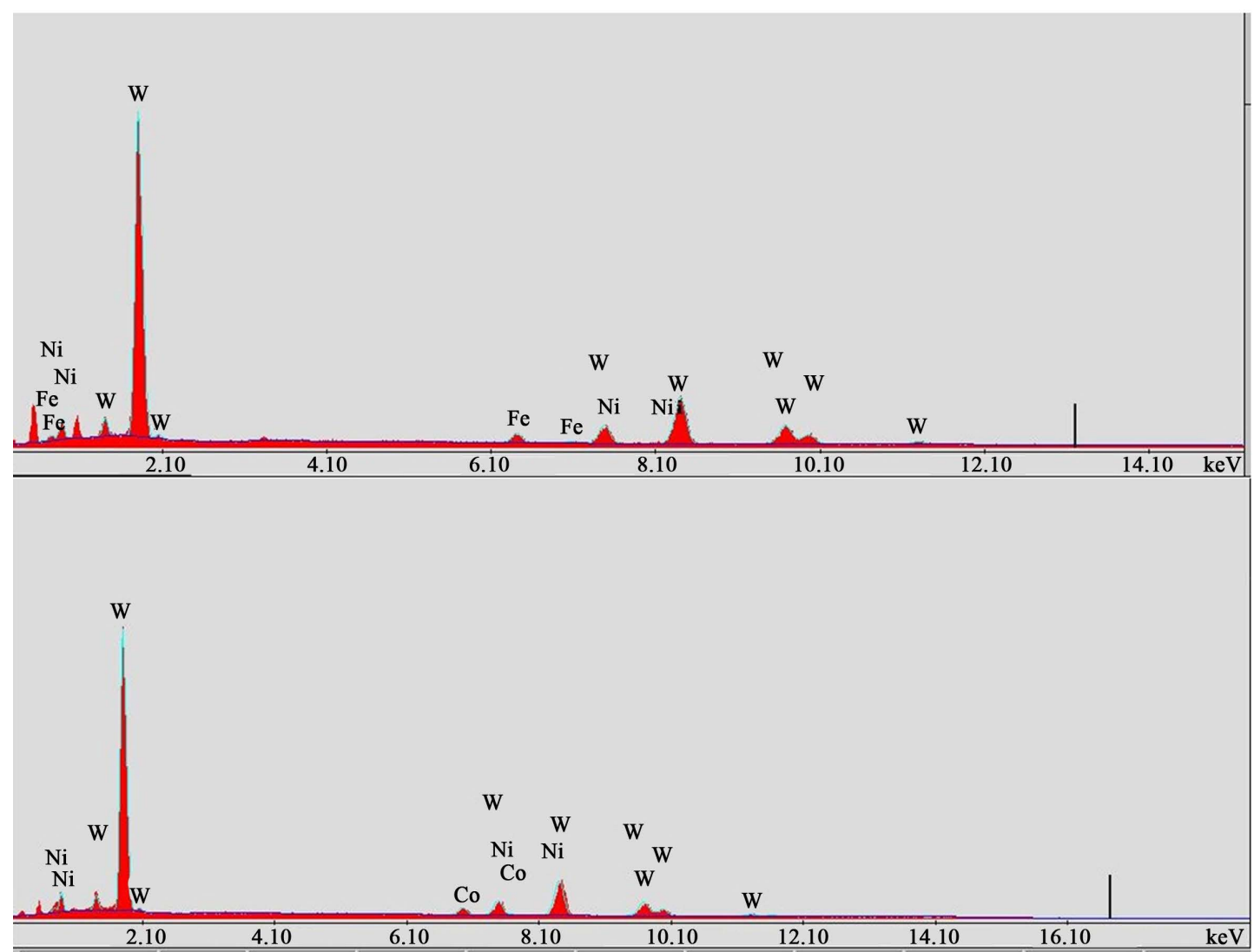

Figure 16. EDX spectrum for the two alloys (a) 90W-7Ni-3Fe and (b) $90 \mathrm{~W}-7 \mathrm{Ni}-3 \mathrm{Co}$ milled for 200 hrs and sintered at $1400{ }^{\circ} \mathrm{C}$.

\subsubsection{Sintered Densities}

The effect of the milling time on the sintered densities for the two alloys $90 \mathrm{~W}-7 \mathrm{Ni}-3 \mathrm{Fe}$ and $90 \mathrm{~W}-7 \mathrm{Ni}-3 \mathrm{Co}$ are shown in Figure 17 and Figure 18, respectively. The results indicated that the variation trend of densities, for the sintered samples with milling time, did not differ from that of the green densities. Figure 17 and Figure 18 showed that, the relative densities for the two alloys exhibited high values corresponding to specific milling times, followed by a decrease with further increase of milling time and decrease in nanocrystallite sizes that reached fine powders [27]. Increasing the sintering temperature enhanced the relative density. At $1200^{\circ} \mathrm{C}$, the milling process was essential for obtaining fine particles sizes; this accordingly formed an appreciable effect on the relative density. This indicated that it is possible to enhance the relative densities of the studies alloys at lower temperatures through milling instead of increasing the sintering temperature.

A comparison between the relative densities of $90 \mathrm{~W}-7 \mathrm{Ni}-3 \mathrm{Fe}$ and $90 \mathrm{~W}-7 \mathrm{Ni}-3 \mathrm{Co}$ at different temperatures, for the two alloys milled for $100 \mathrm{hrs,} \mathrm{is} \mathrm{given} \mathrm{in} \mathrm{Figure} \mathrm{19.} \mathrm{From} \mathrm{the} \mathrm{figure,} \mathrm{the} 90 \mathrm{~W}-7 \mathrm{Ni}-3 \mathrm{Co}$ alloy has a relative density greater than that of 90W-7Ni-3Fe alloy. This could be due to the elemental densities of the cobalt and iron, being 8.9 and $7.8 \mathrm{gm} / \mathrm{cm}^{3}$ respectively. Another interpretation, associated with the cobalt content, lies in the possibility that the sintering of tungsten is profoundly activated by the presence of cobalt in the solid solution; as this chemical element ensures an increase of the diffusion rate [28].

\subsection{Mechanical Characterization}

\subsubsection{Ultra Sonic Measurements}

The ultra-sonic measurements are used as an indicator for the mechanical properties, as a function of milling time and sintering temperature. The measurements were carried out on alloys of unmilled powders as well as on alloys milled for 100, 200 and 400 hrs.

The effect of milling time on the elastic moduli and hardness for the 90W-7Ni-3Fe and 90W-7Ni-3Co alloys, 


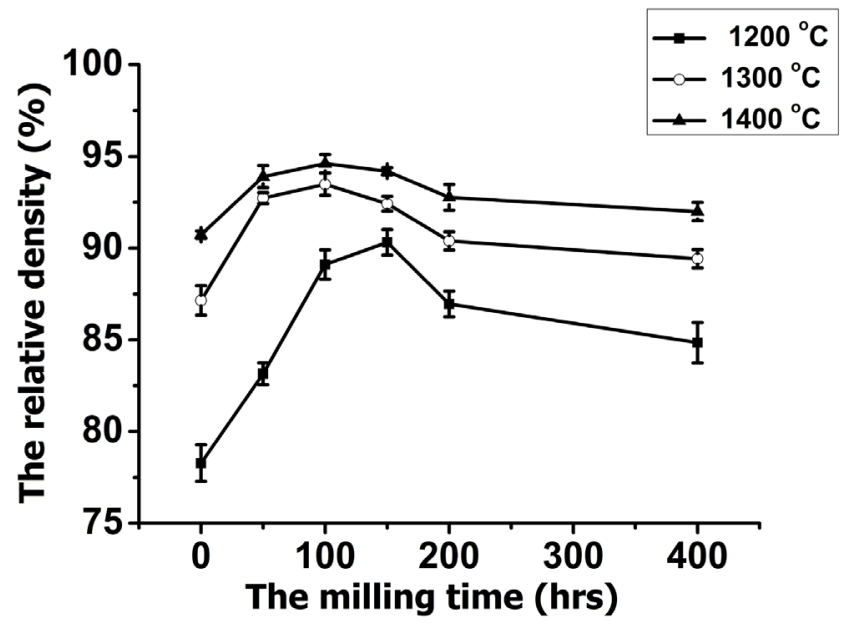

Figure 17. Effect of milling time on the relative density of 90W-7Ni-3Fe alloy at different sintering temperature.

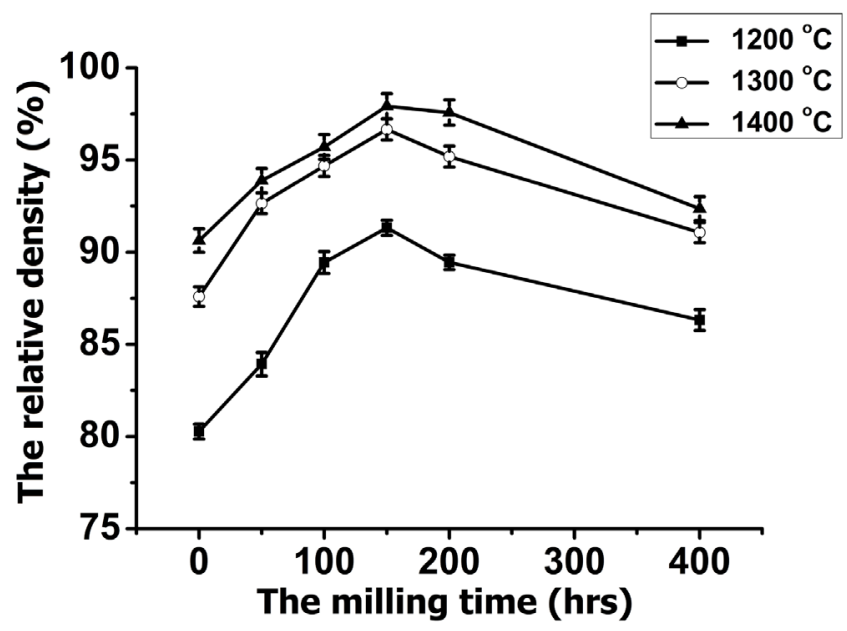

Figure 18. Effect of milling time on the relative density of 90W-7Ni-3Co alloy at different sintering temperature.

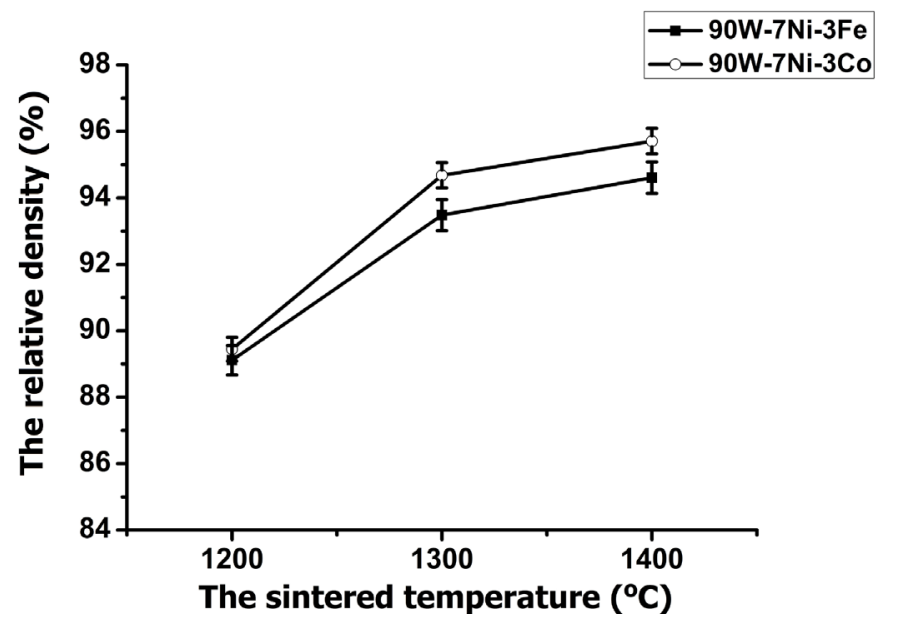

Figure 19. Comparison between the relative density of $90 \mathrm{~W}-7 \mathrm{Ni}-3 \mathrm{Fe}$ and 90W-7Ni-3Co at different temperatures. 
are displayed in Figures 20(a)-(c) and Figures 21(a)-(c), respectively, at different sintering temperatures. The variation in the elastic moduli (Bulk, Shear and Young modulus) as well as the changes in Hardness with milling time, exhibit almost similar trends for both the 90W-7Ni-3Fe and 90W-7Ni-3Co alloys at all sintering temperatures. On the other hand, the variation of the Poisson ratio as a function of milling time exhibits an opposite trend to that of the elastic moduli.
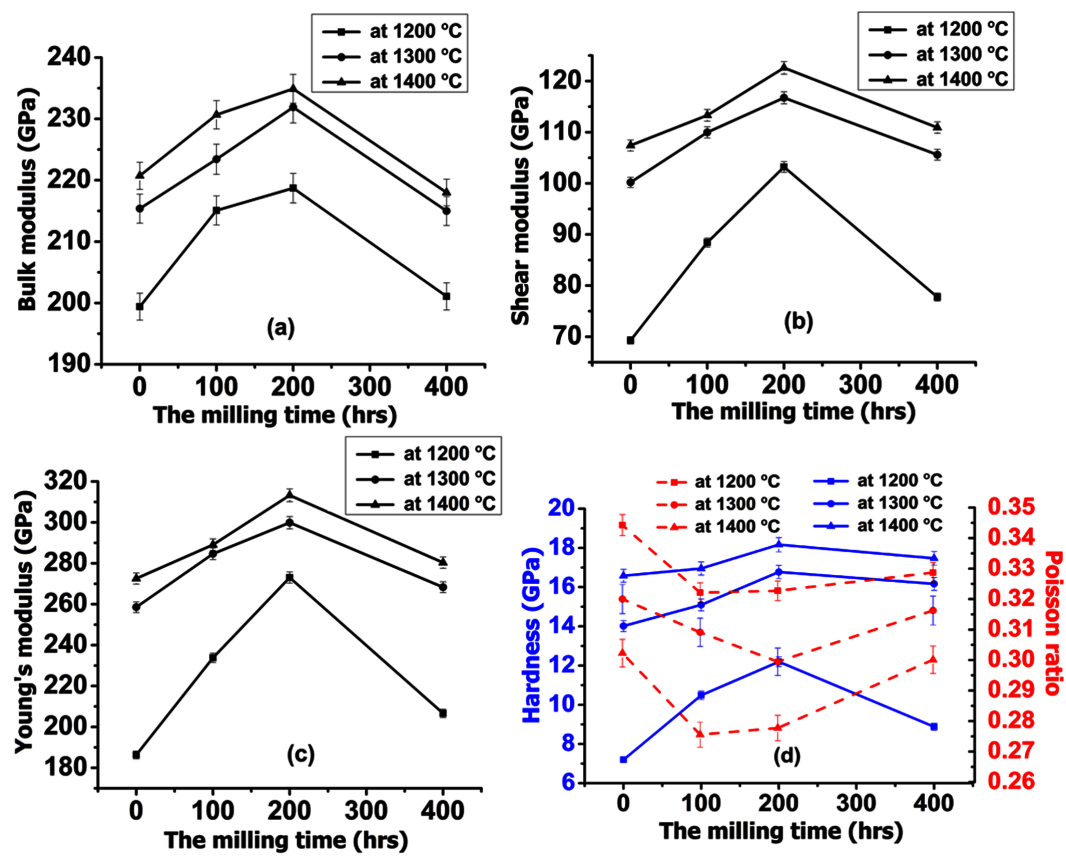

Figure 20. Variation of mechanical properties of 90W-7Ni-3Fe alloy as a function of milling time and at different sintering temperatures (a) Bulk modulus; (b) Shear modulus; (c) Young's modulus and (d) Poisson ratio (dashed line) and Hardness (solid line).
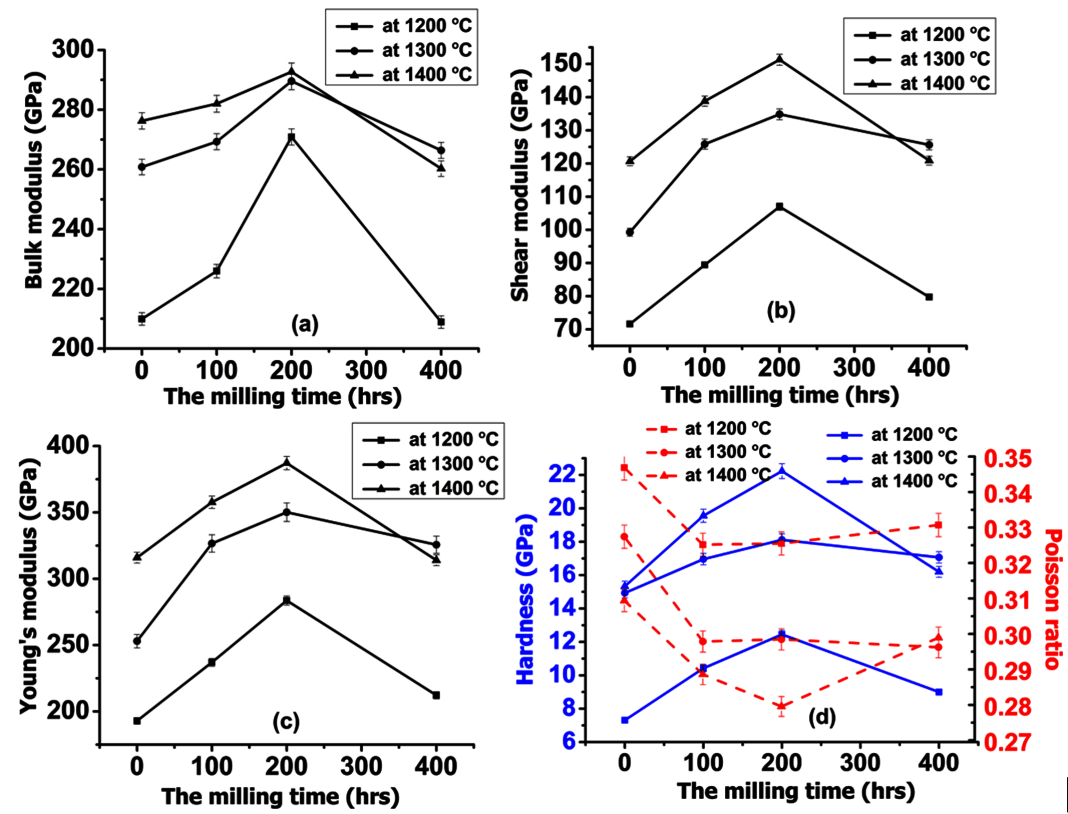

Figure 21. Variation of mechanical properties of 90W-7Ni-3Co alloy as a function of milling time and at different sintering temperatures. (a) Bulk modulus; (b) Shear modulus; (c) Young's modulus; and (d) Poisson ratio (dashed line) and Hardness (solid line). 
The elastic moduli and hardness increased with milling time up to 200 hrs and then decreased with further milling, up to 400 hrs; as shown in Figure 20 and Figure 21. The increase in elastic moduli and hardness with milling time is attributed to the refined microstructure; outcomes of the homogeneous distribution of the binder phase through the alloys, as indicated in Figure 14 and Figure 15. The densities of the sintered alloys played an important role in these results; the trend of the variation of the calculated quantities is similar to that of the measured densities, as given in Figure 17 and Figure 18.

\subsubsection{Vickers Hardness Test}

The hardness values of the 90W-7Ni-3Fe and 90W-7Ni-3Co alloys appear in Figure 22 and Figure 23 respectively. It is clear that, the hardness increases with sintering temperature [29] as well as with the milling time, up to 200 hrs. Further milling causes the hardness to decrease. An evident matching with the results obtained from density; as the density increases, the hardness increases. The behaviors of the two alloys are similar for different temperatures and milling times. Figure 22 and Figure 23 show that the hardness values for the alloys milled above $100 \mathrm{hrs}$ and sintered at $1200^{\circ} \mathrm{C}$, are in the same range as those sintered at $1300^{\circ} \mathrm{C}$ and $1400^{\circ} \mathrm{C}$. This, in turn, confirms the benefit of mechanical alloying in preparing a considerably hard tungsten heavy alloy at $1200^{\circ} \mathrm{C}$, rather than at $1300^{\circ} \mathrm{C}$. The hardness values for the $90 \mathrm{~W}-7 \mathrm{Ni}-3 \mathrm{Co}$ are higher than those for the $90 \mathrm{~W}-$ 7Ni-3Fe alloy; an evident relationship with the sintered densities (Figure 24).

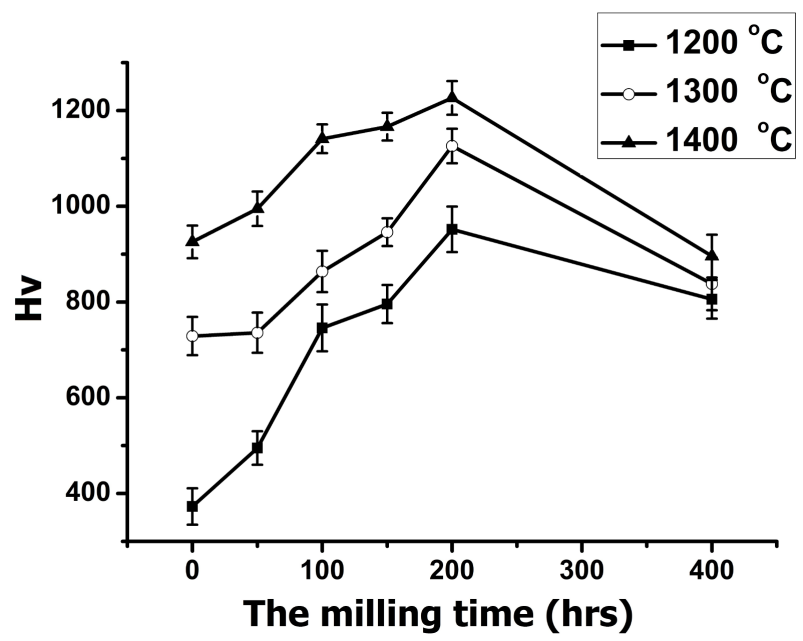

Figure 22. Vicker hardness as a function of milling time at different temperatures for the $90 \mathrm{~W}-7 \mathrm{Ni}-3 \mathrm{Fe}$ alloy.

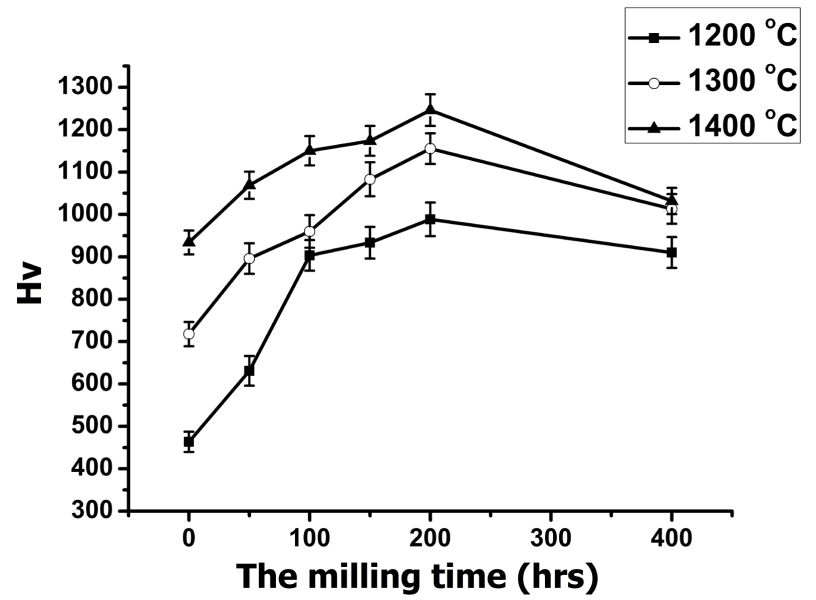

Figure 23. Vicker hardness as a function of milling time at different temperatures for the $90 \mathrm{~W}-7 \mathrm{Ni}-3 \mathrm{Co}$ alloy. 


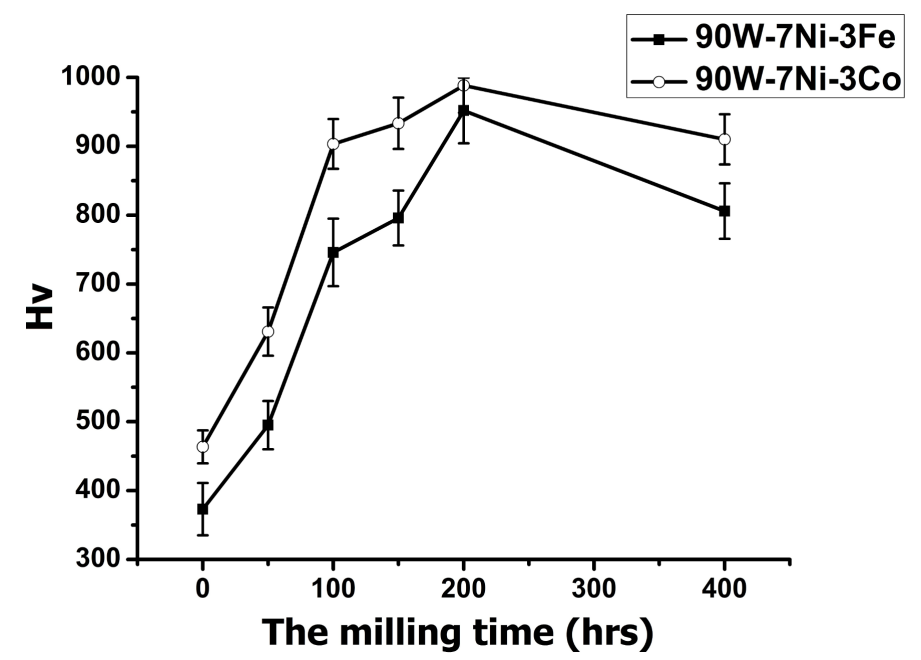

Figure 24. Vicker hardness comparison between the $90 \mathrm{~W}-7 \mathrm{Ni}-3 \mathrm{Fe}$ and $90 \mathrm{~W}-7 \mathrm{Ni}-3 \mathrm{Co}$ alloys sintered at $1200^{\circ} \mathrm{C}$ as a function of milling time.

\subsubsection{Ultrasonic Measurements vs Vickers Hardness}

The correlation between the hardness calculated from ultrasonic velocities and that measured from Vickers equipment is displayed in Figure 25(a) and Figure 25(b). The hardness calculated from ultrasonic results and that measured from Vickers, exhibit similar trend; though the hardness values obtained from the former (ultrasonic) are higher than those obtained from the latter (Vickers). Several trials were carried out in the aim of determining a factor between the ultra-sonic hardness and the Vickers hardness. Evidently, more data was required for better results.

\subsection{Magnetic Characterization}

\section{Magnetization Measurements}

The magnetization field dependence (M-H) for the 90W-7Ni-3Fe alloy, of unmilled powders and those of milled for 100 and 150 hrs, are shown in Figure 26. Moreover the saturation magnetization (Ms) results are listed in Table 2. The measurements were carried out to investigate the effect of milling time, crystallite size and strains, on the magnetic properties of the 90W-7Ni-3Fe alloy. By comparing Figure 26 and the results in Table 2 with those of Figure 6, the following may be deduced: the unmilled sample with crystallite size over $1000 \mathrm{~nm}$ has the highest magnetization (7.31 emu/g), while the milled sample for 100 hrs with the highest strains and nanocrystallite size in the range of ( $23 \%$ and $72 \mathrm{~nm}$ respectively), acquired much less magnetization $(2.34 \mathrm{emu} / \mathrm{g})$. The milled sample for 150 hrs with smaller strains and nanocrystallite size, in the order of $19 \%$ and $64 \mathrm{~nm}$ respectively, has magnetization dependence of $2.05 \mathrm{emu} / \mathrm{g}$. The differences in strain and nanocrystallite size between the unmilled and that milled for 100 hrs are vast. The difference in magnetization is also evident. On the other hand, the differences in strains and nanocrystallite size between the sample milled for 100 hrs and that milled for 150 hrs, are very small. This implies that both the strain and nanocrystallite size have a direct effect on the saturation magnetization (Ms) of the ball milled heavy tungsten alloy. Ball milling the samples decreases the size of the nanocrystallite particles. Moreover, it increases the disorder as well as the defect; hence the formation of magnetically disordered surface of the nanocrystallite particles. Consequently, the large surface-to-volume ratio of the smaller particles leads to the rapid decrease in Ms [30] [31].

\section{Conclusion}

The samples of 90W-7Ni-3Fe and 90W-7Ni-3Co in wt\%, were mechanically alloyed under high purity of argon atmosphere and were sintered under high vacuum. The strains and the relative densities increased with milling time up to 100 hrs and then decreased with further milling. As the crystallite size becomes smaller, the ratio of the volume to the surface area of the crystallite decreases thus leading to a decrease in the density. The volume fraction of $\mathrm{Fe}$, Ni and $\mathrm{Co}$ in the tungsten alloys disappeared for milling times of 400, 200 and 50 hrs re- 

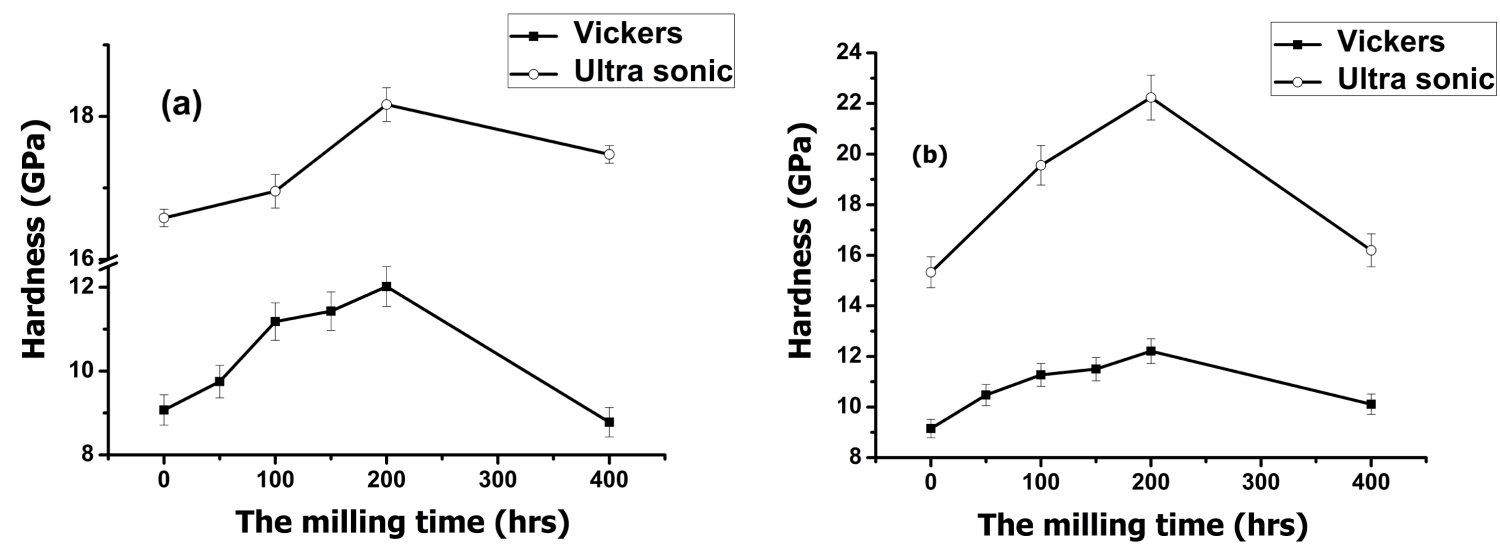

Figure 25. Comparison between Vicker hardness and Hardness calculated from ultrasonic for the (a) 90W-7Ni-3Fe and (b) $90 \mathrm{~W}-7 \mathrm{Ni}-3 \mathrm{Co}$ alloys, sintered at $1400^{\circ} \mathrm{C}$.

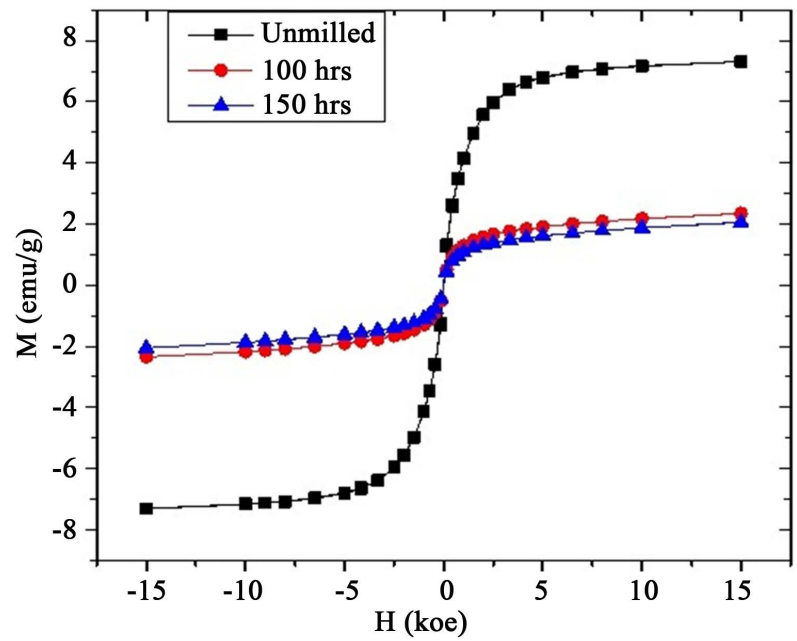

Figure 26. The magnetization field dependence (M-H) for 90W-7Ni-3Fe alloy of unmilled powders and those of milled for 100 and 150 hrs.

Table 2. The saturation magnetization (Ms) for 90W-7Ni-3Fe alloy of unmilled powders and those of milled for 100 and 150 hrs.

\begin{tabular}{cccc} 
Sample & Unmilled & $\mathbf{1 0 0 ~ h r s}$ & $\mathbf{1 5 0}$ hrs \\
\hline Saturation magnitization Ms (emu/g) & 7.31 & 2.34 & 2.05 \\
\hline
\end{tabular}

spectively. Moreover, the Rietveld refinement indicated that the tungsten alloys are formed upon the transformation of $\mathrm{Ni}$ and $\mathrm{Fe}$ or $\mathrm{Ni}$ and $\mathrm{Co}$ into the amorphous phase acting as a binder to the tungsten grains. The tungsten heavy alloys were synthesized and sintered at lower temperature, $1200^{\circ} \mathrm{C}$, than those prepared by the conventional techniques. The elastic moduli and the hardness for the tungsten alloys were calculated using the ultrasonic technique. The elastic moduli and hardness increased with milling time up to 200 hrs and then decreased with further milling. Moreover, the hardness is measured using Vickers technique and the results obtained were correlated with those calculated from the ultrasonic technique. The hardness results obtained showed a similar trend but displayed different values.

\section{References}

[1] Upadhyaya, A. (2001) Processing Strategy for Consolidating Tungsten Heavy Alloys for Ordnance Applications. Materials Chemistry and Physics, 67, 101-110. http://dx.doi.org/10.1016/S0254-0584(00)00426-0 
[2] Ma, Y., Huang, B. and Liu, W. (2005) Status and Development of Tungsten-Based Alloy Research. The Powder Metallurgy Industry, 15, 46-54.

[3] Fan, J., Huang, B. and Qu, X. (2000) W-Ni-Fe Nanostructure Materials Synthesized by High Energy Ball Milling. Transactions of Nonferrous Metals Society of China, 10, 57-59.

[4] Ryu, H.J., Hong, S.H. and Baek, W.H. (1997) Mechanical Alloying Process of 93W-5.6Ni-1.4Fe Tungsten Heavy Alloy. Journal of Materials Processing Technology, 63, 292-297. http://dx.doi.org/10.1016/S0924-0136(96)02638-6

[5] Cai, W.D., Li, Y., Dowding, R.J., Mohamed, F.A. and Lavernia, E.J. (1995) A Review of Tungsten-Based Alloys as Kinetic Energy Penetrator Materials. Reviews in Particulate Materials, 3, 71-131.

[6] Zhang, Z.W., Zhou, J.E., Xi, S.Q., Ran, G. and Li, P.L. (2004) Phase Transformation and Thermal Stability of Mechanically Alloyed W-Ni-Fe Composite Materials. Materials Science and Engineering: A, 379, 148-153. http://dx.doi.org/10.1016/j.msea.2004.02.039

[7] Song, H., Kim, S. and Lee, E.P. (2008) From Advanced Materials. Manufacturing and Testing Information Analysis Center, 3.

[8] Bose, A. and Dowding, R.J. (1997) Tungsten, Refractory Metals and Alloys 4: Processing, Properties and Applications. Proceedings of the 4th International Conference on Tungsten and Refractory Metals and Alloys, Florida, 17-19 November 1997, 17-19.

[9] Rabin, B.H., Bose, A. and German, R.M. (1989) Characteristics of Liquid Phase Sintered Tungsten Heavy Alloys. International Journal of Powder Metallurgy, 25, 21-26.

[10] German, R.M. and Bourguignon, L.L. (1984) Analysis of High Tungsten Content Heavy Alloys. Powder Metallurgy in Defense Technology, 6, 117-131.

[11] Katavik, B. and Nikacevic, M. (2005) Properties of the Cold Swaged and Strain Aged P/M 91W-6Ni-3Co Heavy Alloy. 2nd International Conference on Deformation Processing and Structure of Materials, Belgrade, Serbia and Montenegro, 26-28 May 2005, 135-140.

[12] Hong, S.H., Ryu, H.J. and Baek, W.H. (2002) Matrix Pools in a Partially Mechanically Alloyed Tungsten Heavy Alloy for Localized Shear Deformation. Materials Science and Engineering: A, 333, 187-192. http://dx.doi.org/10.1016/S0921-5093(01)01839-1

[13] Mondala, A., Upadhyayaa, A. and Agrawalb, D. (2010) Effect of Heating Mode on Sintering of Tungsten. International Journal of Refractory Metals and Hard Materials, 28, 597-600. http://dx.doi.org/10.1016/j.ijrmhm.2010.05.002

[14] Benjamin, J.S. (1976) Mechanical Alloying. Scientific American, 234, 40-49. http://dx.doi.org/10.1038/scientificamerican0576-40

[15] Carvalho, P.A., Fonseca, I., Marques, M.T., Correia, J.B., Almeida, A. and Vilar, R. (2005) Characterization of Copper-Cementite Nanocomposite Produced via Mechanical Alloying. Acta Materialia, 53, 967-976. http://dx.doi.org/10.1016/j.actamat.2004.10.042

[16] Krasnowski, M. and Kulik, T. (2008) Nanocomposites Obtained by Mechanical Alloying in Fe-Al-Ti-C System. Journal of Alloys and Compounds, 448, 227-233. http://dx.doi.org/10.1016/j.jallcom.2007.01.013

[17] Lutterotti, L., Scardi, P. and Maistrelli, P. (1992) LSI-A Computer Program for Simultaneous Refinement of Material Structure and Microstructure. Journal of Applied Crystallography, 25, 459-462. http://dx.doi.org/10.1107/S0021889892001122

[18] Lutterotti, L. (2002) MAUD Version 1.85. www.ing.unitn.it/ luttero/maud

[19] Perepechko, I. (1975) Acoustic Method of Investigating Polymers. English Translation, Mir Publishers, Moscow.

[20] Afifi, H. and Marzouk, S. (2003) Ultrasonic Velocity and Elastic Moduli of Heavy Metal Tellurite Glasses. Materials Chemistry and Physics, 80, 517-523. http://dx.doi.org/10.1016/S0254-0584(03)00099-3

[21] Suryanarayana, C. (2001) Mechanical Alloying and Milling. Progress in Materials Science, 46, 1-184.

[22] Dutta, H., Pradhan, S.K. and De, M. (2002) Microstructural Evolution on Ball-Milling Elemental Blends of Ni, Al and Ti by Rietveld's Method. Materials Chemistry and Physics, 74, 167-176. http://dx.doi.org/10.1016/S0254-0584(01)00471-0

[23] Fahlman, B.D. (2007) Material Chemistry. http://dx.doi.org/10.1007/978-1-4020-6120-2

[24] Groza, J.R. and Dowding, R.J. (1996) Nanoparticulate Materials Densification. Nanostructured Materials, 7, 749-768. http://dx.doi.org/10.1016/S0965-9773(96)00046-3

[25] Hewitt, S.A. and Kibble, K.A. (2009) Effects of Ball Milling Time on the Synthesis and Consolidation of Nanostructured WC-Co Composites. International Journal of Refractory Metals and Hard Materials, 27, 937-948. http://dx.doi.org/10.1016/j.ijrmhm.2009.05.006

[26] Hamidi, A.G., Arabi, H. and Rastegari, S. (2011) A Feasibility Study of W-Cu Composites Production by High Pres- 
sure Compression of Tungsten Powder. International Journal of Refractory Metals and Hard Materials, 29, 123-127. http://dx.doi.org/10.1016/j.ijrmhm.2010.09.002

[27] Yusoff, M., Othman, R. and Hussain, Z. (2011) Mechanical Alloying and Sintering of Nanostructured Tungsten Carbide-Reinforced Copper Composite and its Characterization. Materials and Design, 32, 3293-3298.

http://dx.doi.org/10.1016/j.matdes.2011.02.025

[28] German, R.M. (1986) The Effect of the Binder Phase Melting Temperature on Enhanced Sintering. Metallurgical Transactions A, 17, 903-906. http://dx.doi.org/10.1007/BF02643868

[29] Jang, J.S.C., Fwu, J.C., Chang, L.J., Chen, G.J. and Hsu, C.T. (2007) Study on the Solid-Phase Sintering of the Nano-Structured Heavy Tungsten Alloy Powder. Journal of Alloys and Compounds, 434-435, 367-370. http://dx.doi.org/10.1016/j.jallcom.2006.08.215

[30] Goya, G.F., Berquo, T.S., Fonseca, F.C. and Morales, M.P. (2003) Static and Dynamic Magnetic Properties of Spherical Magnetite Nanoparticles. Journal of Applied Physics, 94, 3520-3528. http://dx.doi.org/10.1063/1.1599959

[31] Lin, C.R., Chu, Y.M. and Wang, S.C. (2006) Magnetic Properties of Nanosized $\mathrm{Sr}_{2} \mathrm{CrReO}_{6}$ Powders Prepared by a Combustion Synthesis Process. Materials Letters, 60, 2270-2273. http://dx.doi.org/10.1016/j.matlet.2005.12.124 
Scientific Research Publishing (SCIRP) is one of the largest Open Access journal publishers. It is currently publishing more than 200 open access, online, peer-reviewed journals covering a wide range of academic disciplines. SCIRP serves the worldwide academic communities and contributes to the progress and application of science with its publication.

Other selected journals from SCIRP are listed as below. Submit your manuscript to us via either submit@scirp.org or Online Submission Portal.
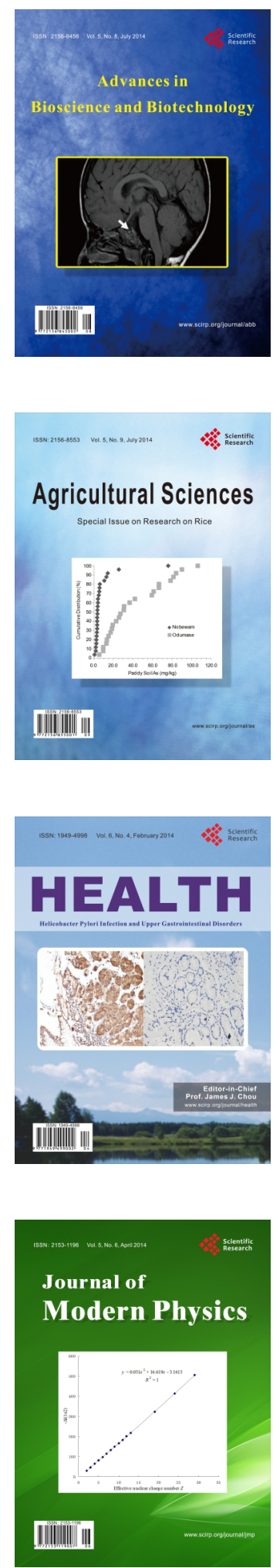
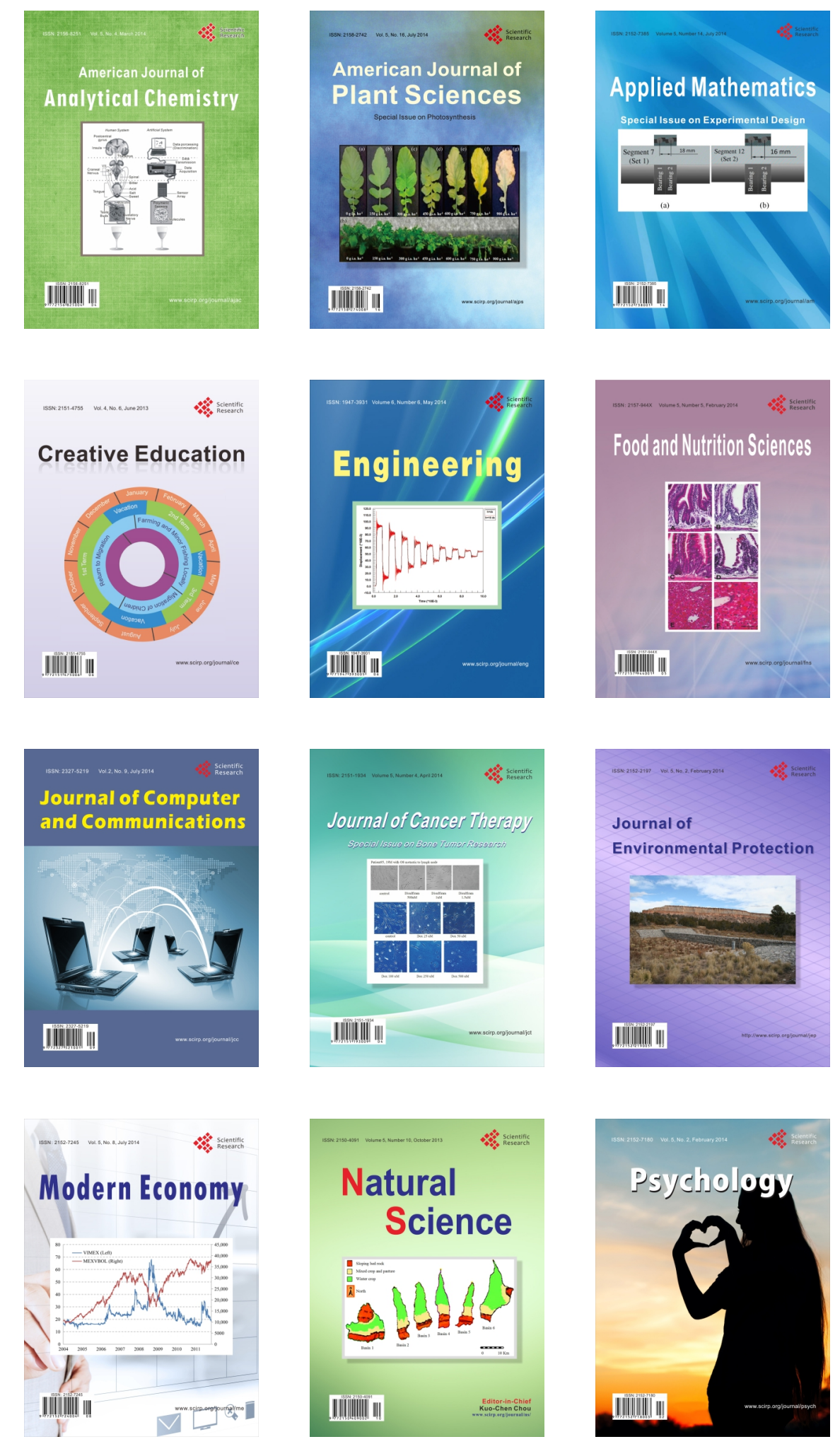